\title{
Mountain radiations are not only rapid and recent: Ancient diversification of South American frog and lizard families related to Paleogene Andean orogeny and Cenozoic climate variations
}

\section{Journal Article}

Author(s):

Boschman, Lydian (D); Condamine, Fabien L.

Publication date:

2022-01

Permanent link:

https://doi.org/10.3929/ethz-b-000521368

Rights / license:

Creative Commons Attribution-NonCommercial-NoDerivatives 4.0 International

Originally published in:

Global and Planetary Change 208, https://doi.org/10.1016/j.gloplacha.2021.103704 
Research Article

\title{
Mountain radiations are not only rapid and recent: Ancient diversification of South American frog and lizard families related to Paleogene Andean orogeny and Cenozoic climate variations
}

\author{
Lydian M. Boschman ${ }^{\mathrm{a}, 1, *}$, Fabien L. Condamine ${ }^{\mathrm{b}, * *, 1}$ \\ a Department of Environmental Systems Science, ETH Zurich, Universitätstrasse 16, 8092 Zurich, Switzerland \\ ${ }^{\mathrm{b}}$ CNRS, UMR 5554 Institut des Sciences de l'Evolution de Montpellier (Université de Montpellier), Place Eugène Bataillon, 34095 Montpellier, France
}

\section{A R T I C L E I N F O}

Editor: Fabienne Marret-Davies

\section{Keywords:}

Andes

Biodiversity

Diversification

Phylogenetics

Neotropics

Uplift

\begin{abstract}
A B S T R A C T
Mountainous areas host a disproportionately large fraction of Earth's biodiversity, suggesting a causal relationship between mountain building and biological diversification. Mountain clade radiations are generally associated with changes in environment, climate, and the increase in heterogeneity therein during mountain building. However, examining the causal relationship between mountain building and diversification is a complex challenge, because isolating the effects of surface uplift from other abiotic (climate) or biotic variables is not straightforward. In this study, we investigate the relative contributions of abiotic climate-driven (temperature) and geology-driven (elevation) drivers on evolutionary rates of ancient groups of organisms in the South American Andes. We present regional curves of Andean elevation based on a recent compilation of paleoelevational data back to the Late Cretaceous, and analyse the diversification history of six Andean frog and lizard families that originated equally far back in time. For two clades (Aromobatidae and Leptodactylidae), we find that they diversified most rapidly during the early phase of mountain building (Late Cretaceous - Paleogene), when the first high-elevation habitats emerged in South America. The diversification of one clade (Centrolenidae) is correlated with Cenozoic temperature variations, with higher speciation rates during warm periods. The last three clades (Dendrobatidae, Hemiphractidae and Liolaemidae) are best explained by environment-independent diversification, although for Liolaemidae, an almost equally strong positive correlation was found between speciation and Andean elevation since the late Eocene. Our findings imply that throughout the long-lived history of surface uplift in the Andes, mountain building drove the diversification of different clades at different times, while not directly affecting other clades. Our study illustrates the importance of paleogeographic reconstructions that capture the complexity and heterogeneity of mountain building in our understanding of the effects that a changing environment plays in shaping biodiversity patterns observed today.
\end{abstract}

\section{Introduction}

Mountainous areas cover approximately $25 \%$ of the surface of the continents, yet are home to $85 \%$ of the world's terrestrial amphibian, bird, and mammal species (Körner et al., 2017; Rahbek et al., 2019b). This strong imbalance in species richness suggests a causal relationship between mountain building and species radiations (Antonelli et al., 2018a; Hoorn et al., 2018; Rahbek et al., 2019a, García-Rodríguez et al., 2021), and such radiations have been documented for various mountainous regions, across disparate groups of organisms (e.g. Drummond et al., 2012; Schwery et al., 2015; Favre et al., 2016; Lagomarsino et al., 2016; Ebersbach et al., 2017; Hutter et al., 2017; Xing and Ree, 2017; Condamine et al., 2018; Esquerré et al., 2019; Muellner-Riehl et al., 2019; Ye et al., 2019; Ding et al., 2020). Mountain clade radiations are generally explained by landscape changes and the associated changes in climate and habitat connectivity, which lead to ecological opportunities and evolutionary innovations (Drummond et al., 2012; Hughes and Atchison, 2015; Favre et al., 2016; Lagomarsino et al., 2016;

\footnotetext{
* Corresponding author at: Department of Earth Sciences, Utrecht University, Princetonlaan 8a, 3584 CB Utrecht, The Netherlands.

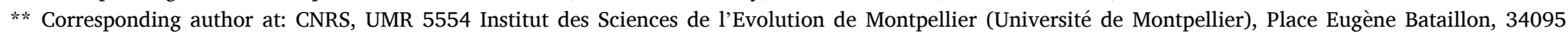
Montpellier, France.

E-mail addresses: 1.m.boschman@uu.nl (L.M. Boschman), fabien.condamine@gmail.com (F.L. Condamine).

1 The authors contributed equally.
} 
Cortés et al., 2018). As a result, mountain clade radiations can be expected to be coeval with the timing of surface uplift. Although geological evidence for uplift histories of mountain ranges come with large uncertainties (Blisniuk and Stern, 2005; Rowley and Garzione, 2007; Botsyun et al., 2020) and uplift is often spatially heterogeneous (e.g. Liu et al., 2016; Spicer et al., 2020; Boschman, 2021), most of the presentday mountain habitats across the globe are thought to have formed gradually throughout the Cenozoic (e.g. Chamberlain et al., 1999, 2012; Nakajima et al., 2006; Fauquette et al., 2015; Liu et al., 2016; Boschman, 2021). It is therefore surprising that documented mountain radiations are found to be generally recent (largely confined to the Pliocene and Pleistocene) and rapid (Linder, 2008; Hughes and Atchison, 2015; Quintero and Jetz, 2018).

The South American Andes, stretching over $\sim 7000 \mathrm{~km}$ from tropical Colombia to sub-polar Patagonia, are the most biodiverse mountains in the world, and the northern, Tropical Andes are considered the most species-rich of all biodiversity hotspots (Myers et al., 2000; Mittermeier et al., 2004). Including some of the most diverse radiations on Earth (Hughes and Eastwood, 2006; Antonelli and Sanmartín, 2011; Madriñán et al., 2013; Lagomarsino et al., 2016; Pérez-Escobar et al., 2017b; Esquerré et al., 2019; Testo et al., 2019), this exceptional species richness is thought to be primarily the result of environmental heterogeneity along both the latitudinal and altitudinal gradients, resulting in a wide variety of climates, landscapes and vegetation types including dry forests and woodlands, tropical rainforests, cloud forests, and permanently or seasonally snow-covered grasslands (Squeo et al., 1993; Josse et al., 2011; Luebert and Weigend, 2014; Cuesta et al., 2017). However, in addition, the paleoclimatic and paleogeographic history of the South American continent and of the Andes in particular is thought to have played a significant role (Gentry, 1982; Antonelli and Sanmartín, 2011). Since the break-up of the supercontinent Pangea and Late Cretaceous separation from Africa, South America remained an isolated "islandcontinent" (Simpson, 1980) until the late Miocene formation of the Panama Isthmus (Montes et al., 2015; O'Dea et al., 2016), and shifted little in latitude. These $\sim 90 \mathrm{Myr}$ of isolation and relative climatic stability may have favoured endemism and the gradual accumulation and preservation of lineages (Antonelli and Sanmartín, 2011). Nonetheless, global-scale climate fluctuations and mountain building led to significant variations in environment (Armijo et al., 2015), affecting the evolution of life. For example, plant diversity has been shown to be positively correlated with Cenozoic temperature, whereby diversity levels during the warm Eocene likely exceeded the Holocene and present (Wilf et al., 2003; Jaramillo et al., 2006). Andean mountain building affected diversity in multiple ways: locally, mountain building is thought to have increased diversity through isolation and allopatric speciation (Hazzi et al., 2018) and ecological adaptation to altitude (Nevado et al., 2018). Regionally, the Andes are often considered to have acted as a "species pump", producing lineages that colonized the surrounding Neotropical lowlands (e.g. Santos et al., 2009; Luebert and Weigend, 2014; Chazot et al., 2019). Moreover, the environmentally diverse slopes of the Andes have repeatedly attracted non-Andean lineages, acting as a "species attractor", increasing species richness through colonization (e.g. Drummond et al., 2012; Chazot et al., 2016; Hutter et al., 2017; Toussaint et al., 2019). These mechanisms are not mutually exclusive because for some clades, a mixture of both processes (colonization in and out of the Andes) has been reported, increasing diversity in both the mountains and the surrounding lowlands (Brumfield and Edwards, 2007; Pérez-Escobar et al., 2017b; Antonelli et al., 2018b).

The many recent (Neogene) documented mountain radiations in and around the Andes are commonly explained in light of recent uplift (Hughes and Eastwood, 2006; Hoorn et al., 2010; Antonelli and Sanmartín, 2011; Madriñán et al., 2013; Luebert and Weigend, 2014; Lagomarsino et al., 2016; Pérez-Escobar et al., 2017b; Esquerré et al., 2019; Testo et al., 2019). This recent uplift is inferred from studies presenting stable isotope paleoaltimetry and fossil leaf physiognomy data from the Eastern Cordillera of Colombia and the eastern Altiplano/
Eastern Cordillera of the central Andes, concluding that rapid uplift occurred in the last $\sim 12$ million years (Gregory-Wodzicki et al., 1998, Gregory-Wodzicki, 2000; Garzione et al., 2008). However, the sedimentary records from the Andean foreland basins indicate that uplift in the Andes initiated already in the Late Cretaceous: $\sim 100$ million years ago (Ma) in Patagonia, and $\sim 70 \mathrm{Ma}$ in the central and northern Andes (Horton, 2018). Moreover, since the studies of Gregory-Wodzicki (1998; 2000) and Garzione et al. (2008), a wealth of paleoaltimetry datasets has been published, depicting a much more complex picture (e.g. Bershaw et al., 2010; Leier et al., 2013; Canavan et al., 2014; Carrapa et al., 2014; Garzione et al., 2014; Hoke et al., 2014; Saylor and Horton, 2014; Quade et al., 2015; Anderson et al., 2015, 2016; Fiorella et al., 2015; Kar et al., 2016; Rohrmann et al., 2016; Colwyn et al., 2019). This body of work, compiled and summarized in Boschman (2021), shows that (i) topography was already in place in Patagonia and in the western ranges along the Pacific coast during the Late Cretaceous and Paleogene, (ii) most of the central and eastern ranges were uplifted during the last 50 to $30 \mathrm{Myr}$, and (iii) uplift migrated further eastwards towards the Subandean zone in the last 10 Myr (Fig. 1). Nonetheless, the idea that the bulk of the topography in the Andes has emerged very recently has persisted in biogeographic and macroevolutionary literature (e.g. Hughes and Eastwood, 2006; Lagomarsino et al., 2016; Pérez-Escobar et al., 2017a, 2017b; Hazzi et al., 2018).

Examining the causal relationship between mountain building and diversification is a complex challenge, because isolating the effects of surface uplift throughout the Cenozoic from other abiotic (climate) or biotic variables is not straightforward (Marx and Uhen, 2010; Ezard et al., 2011, 2016; Condamine et al., 2019a). Moreover, these abiotic and biotic variables are not independent, as mountain building affects both local and regional climate and biotic mechanisms and interactions, which, in turn, have their effects on diversification (Hoorn et al., 2010; Favre et al., 2015; Antonelli et al., 2018a; Ding et al., 2020). Because of this synergy of factors that can affect diversification, there is debate over whether mountain uplift was the primary factor in promoting diversification or that instead, climate change may have played a crucial role (Drummond et al., 2012; Hoorn et al., 2013; Mutke et al., 2014; Hughes and Atchison, 2015; Hutter et al., 2017; Nevado et al., 2018). An important step towards answering such questions is the quantitative correlation between diversification rates and environmental variables. Four studies so far, focussing on radiations of young (Neogene) clades, have attempted this, and found positive correlations between speciation rates and the paleoelevation of the Andes, suggesting a causal link between surface uplift and diversification of the studied clades (Lagomarsino et al., 2016; Pérez-Escobar et al., 2017b; Esquerré et al., 2019; Testo et al., 2019). However, these studies have applied elevationdependent diversification models, without comparing, in a common statistical framework, other diversification models considering the effect of time alone, or of other environmental variables (e.g. temperature). In this study, we embrace the challenge to study the relative contributions of climate-driven abiotic and geology-driven abiotic drivers on evolutionary rates of ancient groups of organisms. We aim at teasing apart the contribution of Andean mountain building, for which we use a novel reconstruction that includes surface uplift since the Late Cretaceous, global climate change, and time, on the diversification of Neotropical frog and lizard groups mostly distributed in the Andes. This study provides the next step towards an understanding of why some lineages diversify extensively during uplift while others do not, and consequently, of our understanding of modern biodiversity patterns including the relationship between topography and species richness.

\section{Materials and methods}

\subsection{Selection of biological groups occurring in the Andes}

We focus in this study on amphibians and squamates that are particularly well diversified in the Andes (Myers et al., 2000; 

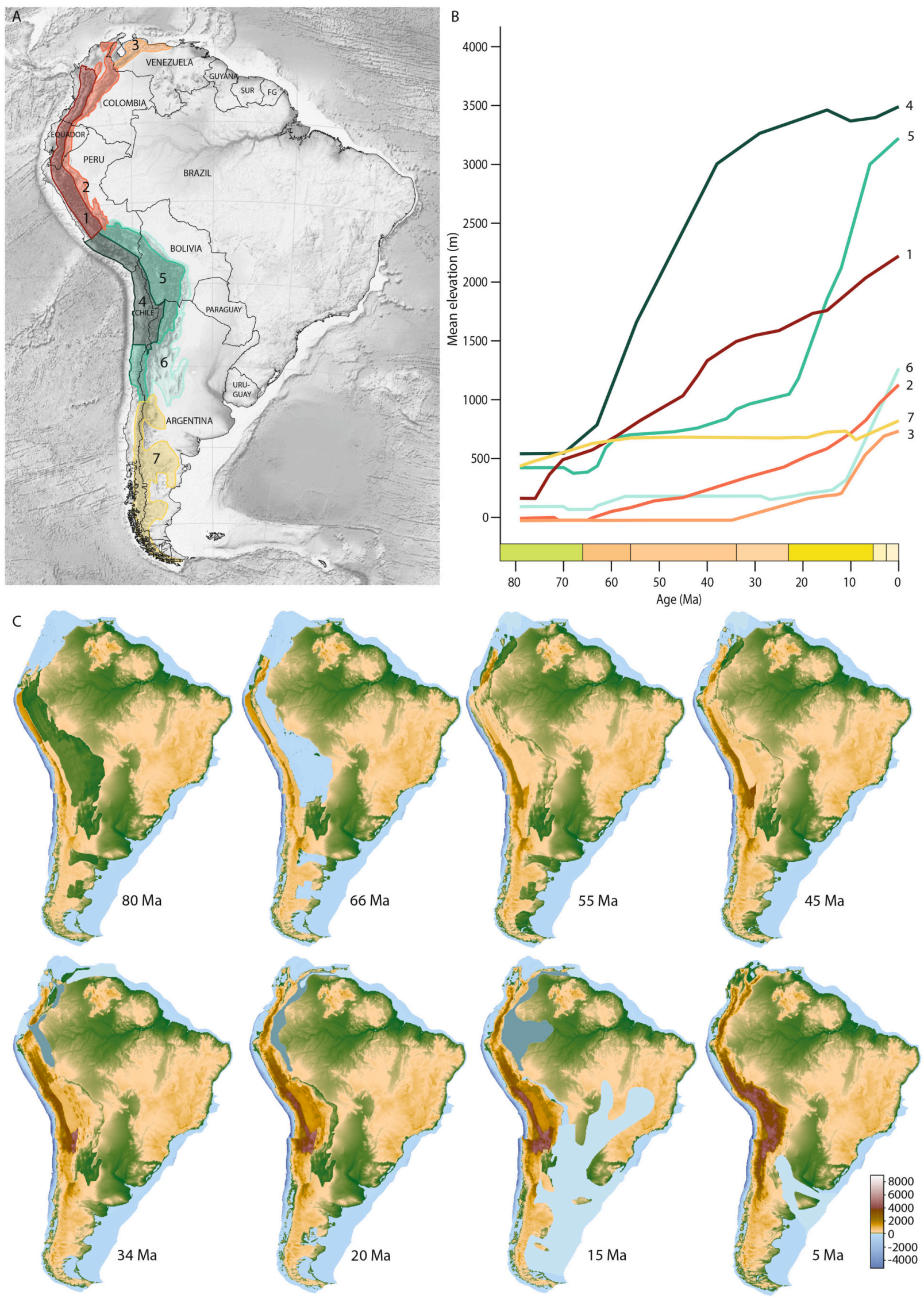

(caption on next page) 


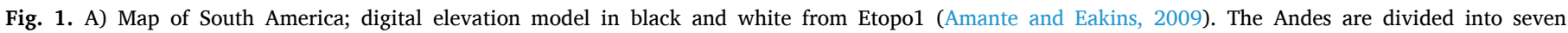

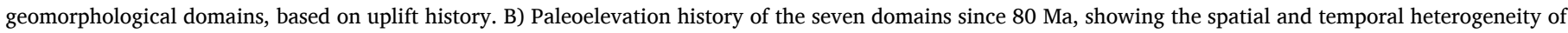

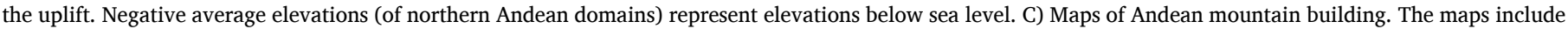

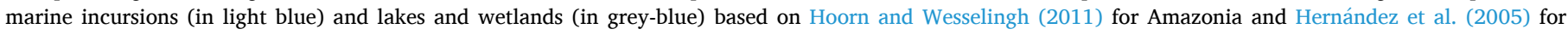

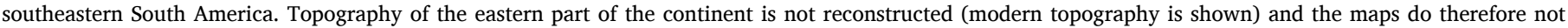

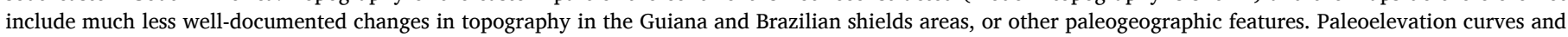

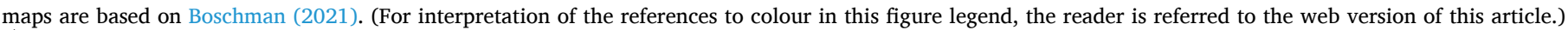

Mittermeier et al., 2004). We compiled a dataset of species-level timecalibrated phylogenies from the literature, including family-level phylogenies with a rich species diversity that sampled at least $65 \%$ of the total species diversity (i.e. sampling fraction of 0.65: ratio of sampled species over known species). For amphibians, we relied on a phylogeny of 2318 hyloid frog species (Hutter et al., 2017), which was constructed with a supermatrix analysis of molecular data. There are 2488 known species of Hyloidea in South America, and 1594 were sampled in the tree (64\%). From this tree, we selected the five best sampled frog families with an average sampling fraction of 0.793 (654 sampled species over 825 known species) and with an average age of origin of $65.4 \mathrm{Ma}$ (Table 1). For squamates, we only selected the lizard family Liolaemidae, which is one of the richest vertebrate Andean radiation with over 320 species (258 sampled), originating around 37 Ma (Table 1). The species-level time-calibrated phylogeny was retrieved from the study of Esquerré et al. (2019). Four of the six selected clades originated during the Late Cretaceous; two are younger and originated during the late Eocene (Liolaemidae) or at the Eocene-Oligocene boundary (Centrolenidae).

The six selected clades are widespread in either the whole (Leptodactylidae), central and southern (Liolaemidae), or northern and north-central Andes (the other four; Supplementary materials). However, except for Liolaemidae, they are not confined to the Andean ranges alone, and for Aromobatidae and Leptodactylidae, the main center of species diversity is in fact outside of the Andes: in Amazonia and the Guiana Shield region, and in the Atlantic Forest, respectively. Species of the genus Adenomera are for example most widely distributed throughout the lowlands of tropical South America east of the Andes (Fouquet et al., 2014). Nonetheless, the origin and geographic range evolution of Aromobatidae and Leptodactylidae are thought to be intimately linked to the Andes (Santos et al., 2009; Hutter et al., 2017), and most species in these clades Aromobatidae and Leptodactylidae are associated with montane environments and are leaf-litter dwelling, which favors allopatry (Fouquet et al., 2013; Santos et al., 2020).

\subsection{Reconstruction of Andean uplift}

We used the reconstruction of paleoelevation in the Andes since 80 Ma of Boschman (2021), which is based on a wide variety of input data, including stable isotope paleoaltimetry, stratigraphy, thermochronology, paleosurfaces, paleobotany, paleontology, palynology and fossil leaf physiognomy. This reconstruction is presented as a series of raster files, one per million-year time step, in 0.1 degree resolution. It thereby provides a very detailed overview of the history of Andean mountain building, including the stark contrast in timing and magnitude of uplift between the different domains of the Andes. To convert this reconstruction (Fig. 1C) into a quantitative time series that we can use in the birth-death modelling, we first condensed it into uplift curves (in m.a.s.l. through geological time) for seven individual geomorphological domains (Fig. 1A, B) for which we describe the history of uplift below. Second, we computed curves of elevation through time for each of the selected clades, whereby we included the elevational history of the Andean ranges that fall within the distribution ranges of the clades (Supplementary materials), resulting in curves for (1) the northern and north-central Andes (domains 1-3 of Fig. 1) for Aromobatidae, Centrolenidae, Dendrobatidae and Hemiphractidae, (2) the central and southern Andes (domains 4-7 of Fig. 1) for Liolaemidea, and (3) the whole Andes (all 7 domains) for Leptodactylidae (Fig. 2).

In the southern (Patagonian) Andes (Fig. 1, domain 7), uplift initiated the earliest, at around 100 Ma (Dalziel et al., 1974; Bruhn and Dalziel, 1977; Kohn et al., 1995; Fosdick et al., 2011; Horton, 2018), and modern elevations were reached at around $55 \mathrm{Ma}$ (Colwyn et al., 2019). During the Miocene, the southern part of the orogen experienced additional uplift, primarily through expanding its width (Davis et al., 1983; Blisniuk et al., 2005, 2006; Giambiagi et al., 2016). In the central Andes, including the world's second largest and highest plateau area (the Altiplano-Puna Plateau), significant uplift initiated along the western margin of the South American plate at around 70 Ma (Horton, 2018). Since then, uplift has migrated eastward, with major phases of uplift in the late Paleocene-Eocene at the western margin of the plateau area (Fig. 1, domain 4), in the Miocene at the eastern margin of the plateau area (domain 5), and active uplift since the middle Miocene in the easternmost Subandean zone (domain 6)(Carrapa et al., 2006, 2014; Scheuber et al., 2006; Uba et al., 2006; Leier et al., 2013; Canavan et al., 2014; Garzione et al., 2014; Fiorella et al., 2015; Quade et al., 2015; Rohrmann et al., 2016). Mountain building in the northern Andes resulted from $\sim 70$ Ma collision of the leading edge of the Caribbean Plate with the South American continental margin at the latitude of what is today Ecuador, and occurred initially only at the location of collision (Montes et al., 2019). Most of the northwestern corner of the South American continent remained below sea level throughout the Late Cretaceous and early Paleogene (Sarmiento-Rojas, 2019). During the Paleogene, uplift slowly migrated to the north and east, reaching the Central Cordillera (part of domain 1) in the Eocene and the Perija Range and Santander Massif in the latest Eocene-Oligocene (part of domain 2). During the early Miocene, the Eastern Cordillera, Garzon Massif (part of

Table 1

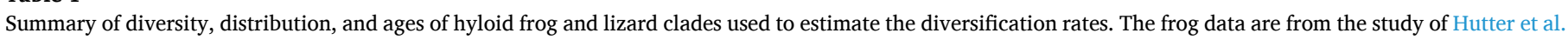

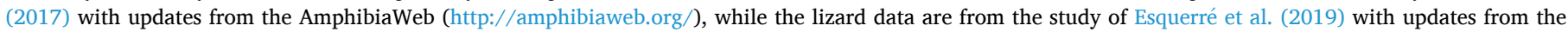
Reptile Database (http://www.reptile-database.org/).

\begin{tabular}{|c|c|c|c|c|c|c|}
\hline Clade & $\begin{array}{l}\text { Age of origin } \\
\text { (Ma) }\end{array}$ & $\begin{array}{l}\text { Number of } \\
\text { genera }\end{array}$ & $\begin{array}{l}\text { Species diversity } \\
\text { (sampled) }\end{array}$ & $\begin{array}{l}\text { Sampling } \\
\text { fraction }\end{array}$ & $\begin{array}{l}\text { Elevational range } \\
(\mathrm{m})\end{array}$ & Distribution range \\
\hline Aromobatidae & 67.18 & 5 & 127 (118) & 0.929 & $500(0-3300)$ & $\begin{array}{l}\text { Northern and central Andes, Amazonia, } \\
\text { Atlantic Forest }\end{array}$ \\
\hline Centrolenidae & 33.4 & 12 & $160(128)$ & 0.8 & $1400(0-3501)$ & $\begin{array}{l}\text { Northern and central Andes, Amazonia, } \\
\text { Atlantic Forest }\end{array}$ \\
\hline Dendrobatidae & 67.35 & 16 & $197(136)$ & 0.69 & $840(0-3799)$ & Northern and central Andes, Amazonia \\
\hline Hemiphractidae & 80.69 & 6 & $118(86)$ & 0.729 & $1640(0-4600)$ & Northern and central Andes, Atlantic Forest \\
\hline Leptodactylidae & 78.07 & 14 & $223(186)$ & 0.834 & $500(0-4480)$ & whole South America \\
\hline Liolaemidae & 36.9 & 3 & $321(258)$ & 0.804 & $2150(20-5000)$ & Central and southern Andes \\
\hline
\end{tabular}




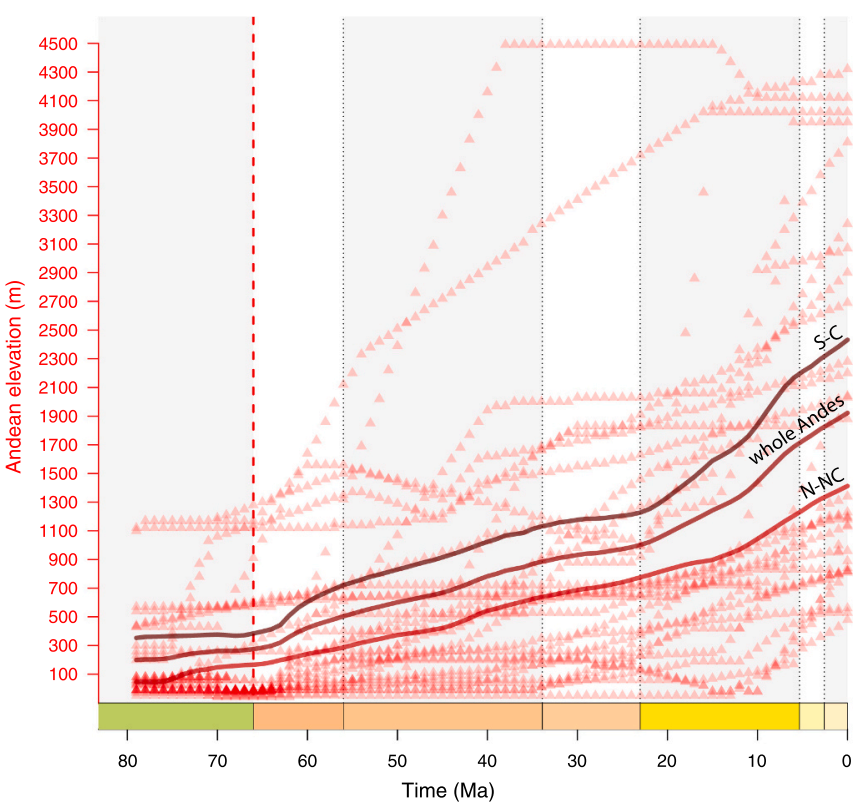

Fig. 2. The Andean elevation curves used to estimate Neotropical diversification over the last $80 \mathrm{Myr}$. Red triangles represent data from individual geomorphological domains as reconstructed by Boschman (2021); solid lines represent the smoothed curves that are used as input in the elevation-dependent birth-death models (see descriptions in 2.4 and 2.5). S-C: southern and central Andes (domains 4-7 of Fig. 1), paleoelevation curve for Liolaemidea; N-NC: northern and north-central Andes (domains 1-3 of Fig. 1), paleoelevation curve for Aromobatidae, Centrolenidae, Dendrobatidae and Hemiphractidae; whole Andes (all 7 domains of Fig. 1) curve for Leptodactylidae. (For interpretation of the references to colour in this figure legend, the reader is referred to the web version of this article.)

domain 2) and Merida Andes (domain 3) experienced pronounced uplift, and uplift in these latter eastern ranges intensified since the Miocene (Gómez et al., 2005a, 2005b; Villagómez et al., 2011; Anderson et al., 2015, 2016; Bermúdez et al., 2017; Horton, 2018).

\subsection{Temperature data}

To capture the major trends in global climate through time throughout the clades' evolutionary histories, we computed a temperature curve based on $\delta^{18} \mathrm{O}$ data measured from deep-sea benthic foraminifera shells preserved in oceanic sediments (Fig. 3). For the Cenozoic, we used the dataset from Westerhold et al. (2020, available at: doi:10.1594/PANGAEA.917717), and for the Cretaceous (80-66 Ma), the dataset from Veizer and Prokoph (2015, available at: doi:10.1016/j. earscirev.2015.03.008). To convert $\delta^{18} \mathrm{O}$ measurements to temperature values, we used the equations of Hansen et al. (2013), which convert $\delta^{18} \mathrm{O}$ to deep-ocean temperatures $\left(\mathrm{T}_{\mathrm{do}}\right)$ and subsequently, to surface temperatures $\left(\mathrm{T}_{\mathrm{S}}\right)$; these equations are provided in the supplementary materials 1 . We then summarized these data into a continuous estimate of temperature through time through calculation of a smoothing spline (degrees of freedom: 80). While each individual data point is subject to certain biases (e.g. some of them do not account for sea-level fluctuations, which are important during periods of large-scale glaciations, Cramer et al., 2011), the spline curve smoothens such biases, as well as geographical variations, providing a reliable estimate of global temperature trends (Veizer and Prokoph, 2015). The surface temperature curve reflects planetary-scale climatic trends that can be expected to have led to temporally coordinated diversification changes in several clades rather than local or seasonal fluctuations (Erwin, 2009; Hannisdal and Peters, 2011; Mayhew et al., 2012; Condamine et al., 2019a).

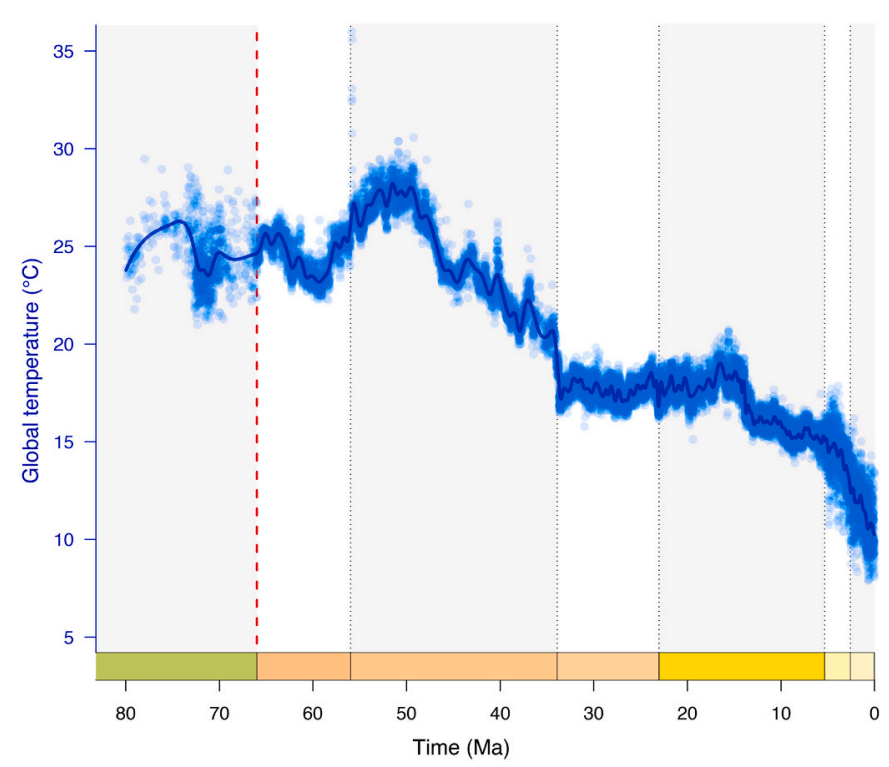

Fig. 3. The global surface temperature curve used to estimate Neotropical diversification over the last 80 Myr. The trend of temperature is based on oxygen isotope ratios in benthic foraminifera shells; data from Veizer and Prokoph (2015) for the Late Cretaceous, and Westerhold et al. (2020) for the Cenozoic. Isotope ratios are converted to surface temperatures using the equations from Hansen et al. (2013). Blue circles represent data from individual $\delta^{18} \mathrm{O}$ measurements; the solid line represents the smoothed curve that is used as input in the temperature-dependent birth-death models (see descriptions in 2.4 and 2.5). (For interpretation of the references to colour in this figure legend, the reader is referred to the web version of this article.)

\subsection{Modelling the effects of environmental change on diversification}

Many studies have shown that the environment, shaped by long-term climate change and plate tectonics, plays a prominent role in the diversification of species over evolutionary and geological time scales (e.g. Mayhew et al., 2012; Zaffos et al., 2017). Yet, these studies have mostly based their conclusions on descriptive comparisons between dated speciation or extinction events estimated from fossil or phylogenetic data and paleoenvironmental curves (e.g. Delsuc et al., 2004; Antonelli et al., 2009; Eronen et al., 2015; Fan et al., 2020). Such an approach is suitable for events that occurred "instantaneously" in the context of geological time (i.e. within a million year), such as mass extinctions, but may not always be appropriate when comparing slower environmental changes. Most climate "events", such as the Eocene Climatic Optimum ( $\sim 56-46 \mathrm{Ma})$, the middle Miocene climatic optimum $(\sim 17-15 \mathrm{Ma})$ or the overall Cenozoic cooling trend, take place over longer timescales (Veizer and Prokoph, 2015; Westerhold et al., 2020), and so do environmental changes related to plate tectonics such as the uplift of the Andes, which took place over the last 100 Myr (Boschman, 2021). Furthermore, geological events are often intrinsically related to climate change, which complicates linking isolated environmental changes to single diversification events. For example, the uplift of the Andes affected climate in the eastern Pacific Ocean and above the South American continent (Sepulchre et al., 2010; Armijo et al., 2015), and uplift of the Qinghai-Tibetan Plateau shaped the Asian monsoon system (Molnar et al., 1993; An et al., 2001; Favre et al., 2015). In addition, the aforementioned descriptive approaches generally use phylogenetic trees — branching trees that represent the evolutionary relationships among species - that have uncertainties in their configuration and in age estimates of the speciation events, which makes comparison between a given environmental variable and the diversification processes ambiguous. Finally, these approaches do not quantify the long-term effect of environmental factors in shaping diversification rates, but rather look for punctuated change in diversification. 
To account for these issues, methods have been developed in recent years to quantitatively explore factors that are potentially linked to speciation and/or extinction of lineages throughout geological and evolutionary time, thereby providing new opportunities to address questions about the mechanisms that shape diversity patterns (Egan and Crandall, 2008; Condamine et al., 2013; Davis et al., 2016). Such methods have been made possible by the increased availability of statistical tools to analyse molecular and fossil data, and accessibility of time-calibrated molecular phylogenies. We focus in this study on phylogeny-based approaches, but note that these are beginning to converge with fossil-based approaches in their conceptual development and inferences to estimate temporal variations of diversification rates (Morlon et al., 2011; Silvestro et al., 2014, 2019), and evolutionary response to variations of the environment (Condamine et al., 2013; Silvestro et al., 2015; Lehtonen et al., 2017).

The approach used in this study, developed by Condamine et al. (2013, 2019a) and hereafter termed the environment-dependent diversification model, builds on time-dependent diversification models (Nee et al., 1994; Morlon et al., 2011), but allows speciation and extinction rates to depend not only on time but also on an external variable (which may vary through time). This methodology is implemented in the R-package RPANDA (Morlon et al., 2016). Clades are assumed to evolve under a birth-death process, in which both speciation and extinction follow a Poisson process, meaning that the expected waiting time to an event follows an exponential distribution (Nee, 2006). As a result, we assume the speciation and extinction functions to be exponential. Speciation $(\lambda)$ and extinction $(\mu)$ rates can vary through time, and both can be influenced by one or several environmental variables (here: temperature ( $T$ ), and Andean elevation $(A)$ ) that also vary through time. We consider the phylogeny of $n$ species sampled from the present, and allow for the possibility that some extant species are not included in the sample by assuming that each extant species was sampled with probability $f \leq 1$. Time is measured from the present to the past such that it denotes branching times in the phylogeny.

\subsection{Analyzing the diversification of Andean clades}

In this study, we fitted 14 diversification models to each of the six selected phylogenies using maximum likelihood (Stadler, 2013; Morlon,
2014). We consider four types of models with diversification rates that are constant (2 models), time-varying (4 models), temperaturedependent (4 models), and elevation-dependent (4 models) (Fig. 4A; Table 2). These models are fitted by maximum likelihood using the fit $b d$ (for the time-constant and time-varying models) and fit_env functions (for the temperature- and elevation-dependent models) from the Rpackage RPANDA 1.9 (Morlon et al., 2016). We accounted for missing species by specifying the sampling fraction corresponding to each phylogeny. We used the "crown" condition, which conditions the likelihood of a speciation event at the crown age and survival of the two daughter lineages.

In the time-dependent models, $\lambda$ or both $\lambda$ and $\mu$ vary as a continuous function of time (Table 2): $\lambda(\mathrm{t})=\lambda_{0} \mathrm{e}^{\alpha \mathrm{t}}$ or $\mu(\mathrm{t})=\mu_{0} \mathrm{e}^{\beta \mathrm{t}}$, where $\lambda_{0}\left(\mu_{0}\right)$ is the speciation (extinction) rate at present. A positive $\alpha(\beta)$ reflects a slowdown of speciation (extinction) towards the present, while a negative $\alpha$ ( $\beta$ ) reflects a speed-up of speciation (extinction) towards the present, and the sign and value of $\alpha$ and $\beta$ depends on the data and model optimization. In the environment-dependent models, speciation rates, extinction rates, or both vary as a continuous function of Andean elevation $A$ (Fig. 2) or temperature $T$ (Fig. 3), for which the curves are computed using a spline interpolation which the degree of freedom set to 80 ( $\mathrm{df}=80$ in the fit_env function). We consider the same exponential dependency as above, but with $t$ replaced by $T(t)$ or $A(t)$. In this case $\lambda_{0}\left(\mu_{0}\right)$ is the expected speciation (extinction) rate under a temperature of $0{ }^{\circ} \mathrm{C}$ or an altitude of $0 \mathrm{~m}$, and $\alpha(\beta)$ measures the sign and strength of the temperature or paleoelevation dependence (Fig. 4B). A positive $\alpha(\beta)$ indicates that speciation (extinction) rates are higher under warm climatic conditions or when elevations were high, while a negative $\alpha(\beta)$ indicates that speciation (extinction) rates are higher under cold climatic conditions or when elevations were low (Fig. 4B).

We fitted each of the models to each phylogeny by maximum likelihood, starting with the simplest (constant rate) models and progressively increasing in complexity. The maximum-likelihood algorithm optimizes parameter values (of $\lambda_{0}, \mu_{0}, \alpha$ and/or $\beta$ ) that maximize the probability of the observed data (the phylogenetic tree) under a given model. Because these optimization algorithms can be sensitive to the choice of initial parameter values (they can converge to local optima in the vicinity of the initial parameter values), we informed the initial parameter values of more complex models by those previously estimated
A

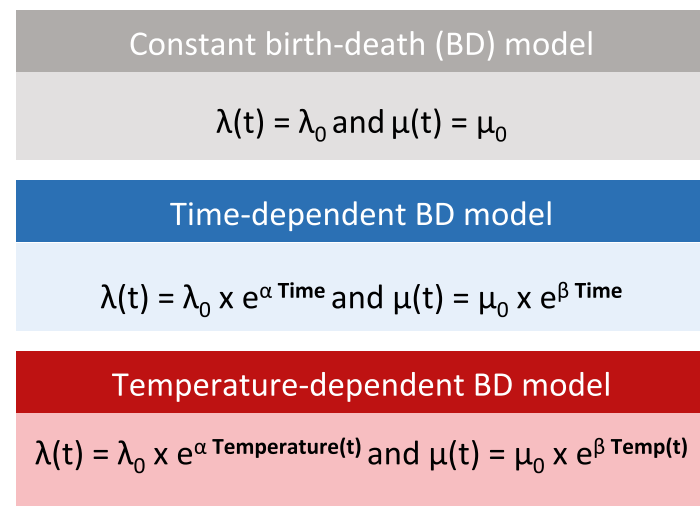

Elevation-dependent BD model

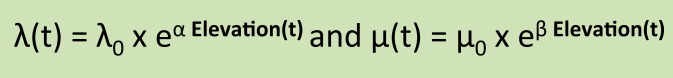

B

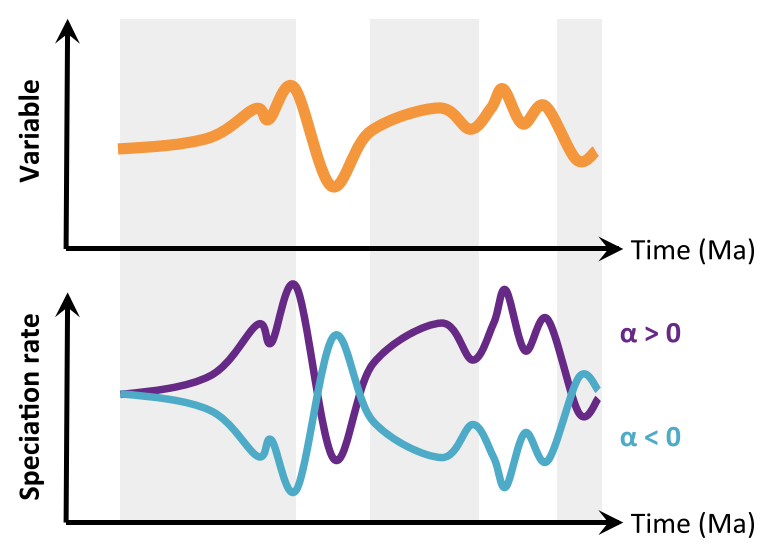

$\lambda_{0} / \mu_{0}=$ speciation / extinction rate for a value of 0 (at present for Time)

$\alpha / \beta=$ strength and sense of the dependency for $\lambda / \mu$

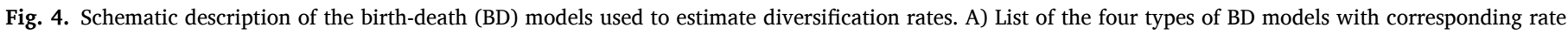

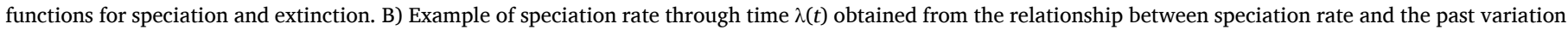

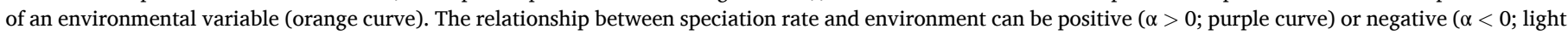

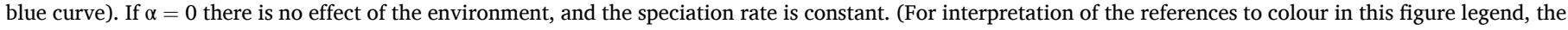
reader is referred to the web version of this article.) 
Table 2

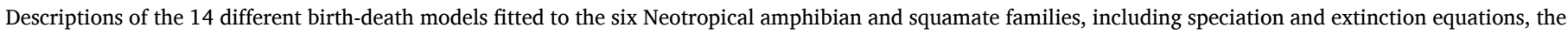
number of free parameters to optimize by maximum likelihood, and the acronym as used in Table 3, which reports the results per family.

\begin{tabular}{|c|c|c|c|c|}
\hline Type of model & Model description & Model equation & Number of parameters & Model acronym in Table 3 \\
\hline \multirow[t]{2}{*}{ Constant-rate models } & Constant speciation and no extinction & $\lambda(\mathrm{t})=\lambda_{0}$ and $\mu(\mathrm{t})=0$ & 1 & BCST \\
\hline & Constant speciation and constant extinction & $\lambda(t)=\lambda_{0}$ and $\mu(t)=\mu_{0}$ & 2 & BCSTDCST \\
\hline \multirow[t]{4}{*}{ Time-dependent models } & Speciation variable and no extinction & $\lambda(\mathrm{t})=\lambda_{0} \mathrm{e}^{\alpha \mathrm{t}}$ and $\mu(\mathrm{t})=0$ & 2 & BTimeVar \\
\hline & Speciation variable and constant extinction & $\lambda(\mathrm{t})=\lambda_{0} \mathrm{e}^{\alpha \mathrm{t}}$ and $\mu(\mathrm{t})=\mu_{0}$ & 3 & BTimeVarDCST \\
\hline & Constant speciation and extinction variable & $\lambda(\mathrm{t})=\lambda_{0}$ and $\mu(\mathrm{t})=\mu_{0} \mathrm{e}^{\beta \mathrm{t}}$ & 3 & BCSTDTimeVar \\
\hline & Both speciation and extinction variable & $\lambda(\mathrm{t})=\lambda_{0} \mathrm{e}^{\alpha \mathrm{t}}$ and $\mu(\mathrm{t})=\mu_{0} \mathrm{e}^{\beta \mathrm{t}}$ & 4 & BTimeVarDTimeVar \\
\hline \multirow[t]{4}{*}{ Temperature-dependent models } & Speciation variable and no extinction & $\lambda(\mathrm{t})=\lambda_{0} \mathrm{e}^{\alpha \mathrm{T}(\mathrm{t})}$ and $\mu(\mathrm{t})=0$ & 2 & BTempVar \\
\hline & Speciation variable and constant extinction & $\lambda(\mathrm{t})=\lambda_{0} \mathrm{e}^{\alpha \mathrm{T}(\mathrm{t})}$ and $\mu(\mathrm{t})=\mu_{0}$ & 3 & BTempVarDCST \\
\hline & Constant speciation and extinction variable & $\lambda(\mathrm{t})=\lambda_{0}$ and $\mu(\mathrm{t})=\mu_{0} \mathrm{e}^{\beta \mathrm{T}(\mathrm{t})}$ & 3 & BCSTDTempVar \\
\hline & Both speciation and extinction variable & $\lambda(\mathrm{t})=\lambda_{0} \mathrm{e}^{\alpha \mathrm{T}(\mathrm{t})}$ and $\mu(\mathrm{t})=\mu_{0} \mathrm{e}^{\beta \mathrm{T}(\mathrm{t})}$ & 4 & BTempVarDTempVar \\
\hline \multirow[t]{4}{*}{ Elevation-dependent models } & Speciation variable and no extinction & $\lambda(\mathrm{t})=\lambda_{0} \mathrm{e}^{\alpha \mathrm{A}(\mathrm{t})}$ and $\mu(\mathrm{t})=0$ & 2 & BAndesVar \\
\hline & Speciation variable and constant extinction & $\lambda(\mathrm{t})=\lambda_{0} \mathrm{e}^{\alpha \mathrm{A}(\mathrm{t})}$ and $\mu(\mathrm{t})=\mu_{0}$ & 3 & BAndesVarDCST \\
\hline & Constant speciation and extinction variable & $\lambda(\mathrm{t})=\lambda_{0}$ and $\mu(\mathrm{t})=\mu_{0} \mathrm{e}^{\beta \mathrm{A}(\mathrm{t})}$ & 3 & BCSTDAndesVar \\
\hline & Both speciation and extinction variable & $\lambda(\mathrm{t})=\lambda_{0} \mathrm{e}^{\alpha \mathrm{A}(\mathrm{t})}$ and $\mu(\mathrm{t})=\mu_{0} \mathrm{e}^{\beta \mathrm{A}(\mathrm{t})}$ & 4 & BAndesVarDAndesVar \\
\hline
\end{tabular}

on simpler models. The 14 tested models are not all nested, and we used the corrected Akaike Information Criterion (AICc; Burnham and Anderson, 2002) to compare models. The AICc is useful to compare the probability of observing branching times as explained by various individual paleoenvironmental variables (Condamine et al., 2015, 2018, 2019a). A series of models can be designed to quantify the effect that various environmental variables, taken in isolation, had on diversification. We thus compared the AICc scores for the best-fit models between multiple environmental variables (temperature, Andean uplift) to determine which has the strongest effect on diversification. The bestfitting model is selected using Akaike weights (AIC $\omega$ ).

\section{Results}

Within the six clades, we found that three clades primarily supported an environment-independent model of diversification (Figs. 5 and 6, Table 3): the constant-rate model best fitted the diversification of Dendrobatidae (AIC $\omega=0.523$; AIC $\omega=0.286$ for the second best model that is a temperature-dependent model, Fig. $5 \mathrm{E}, \mathrm{F}$ ) and of Hemiphractidae (AIC $\omega=0.447$; AIC $\omega=0.288$ for the second best model that is an elevation-dependent model, Fig. 6A, B), while the time-dependent model best explains the diversification of Liolaemidae (AIC $\omega=0.447$; AIC $\omega=0.394$ for the second best model that is an elevation-dependent model, Fig. 6E, F). The remaining three clades showed statistical support for an environment-dependent model of diversification with either a temperature-dependent model for Centrolenidae (AIC $\omega=0.882$; AIC $\omega$ $=0.096$ for the second best model that is an elevation-dependent model, Fig. 5C, D), or an elevation-dependent model for Aromobatidae (AIC $\omega=$ 0.549; AIC $\omega=0.286$ for the second best model that is a time-dependent model, Fig. 5A, B), and Leptodactylidae (AIC $\omega=0.536$; AIC $\omega=0.279$ for the second best model that is a constant-rate model, Fig. 6C, D).

For Centrolenidae, the temperature-dependent model estimated a positive correlation between speciation rates and global temperatures $(\alpha=0.2013$, Fig. 5D), which translates into faster speciation during warmer periods. For the other five clades, the temperature-dependent model was not selected as the best-fit model, but did indicate a positive correlation between speciation rates and global temperatures, except for Liolaemidae (Table 3). The elevation-dependent model estimated a negative correlation between speciation rates and Andean elevation for both Aromobatidae and Leptodactylidae $(\alpha=-6.00 \mathrm{E}-04$, -0.001 , respectively, Figs. 5B and 6D). This implies that these groups diversified faster in the early stages of the Andean orogeny. Moreover, the model for Leptodactylidae indicated a negative correlation between extinction rates and Andean elevation $(\beta=-0.0018)$, which suggests higher extinction rates during the initial phase of mountain building.

Except for Liolaemidae, all elevation-dependent models (whether best-fit or not) estimated negative correlations between speciation rates and Andean elevation (Table 3), meaning high speciation rates during low elevations, and thus, during the early stages of the Andean orogeny. For Liolaemidae, one of the two younger $(\sim 37 \mathrm{Ma})$ clades, the best fitmodel is a time-dependent model, which estimated an increase in speciation through time $(\alpha=-0.0584)$ with a speciation rate of $\lambda_{0}=$ 0.3491 events/lineage/Myr at present (Fig. 6F). However, it is important to mention the second best-fitting model indicating a positive correlation ( $\alpha=0.0011$ ) between speciation and Andean elevation, because the difference between the two best models is small $(\triangle \mathrm{AICc}=0.256$, Table 3). Liolaemidae is the only studied clade showing a positive relationship between speciation and Andean elevation (Fig. 6F). This result suggests higher speciation rates during the later stages of Andean orogeny, when the Andes were higher.

The support for the models best explaining the diversification of the six clades is variable (AIC $\omega$ ranging from 0.231 to 0.60 , with a mean of 0.316 ; Table 3$)$, but always above the 0.071 weight $(1 / 14)$ that would be expected if all models were equally likely. Nonetheless, after selecting the best-fitting model from each of the three main types (non-environment-dependent [including constant and time-dependent], temperature-dependent or elevation-dependent), and comparing only these three, the strength of support of the best-fitting models was reasonably high (mean AIC $\omega$ of 0.473 for non-environment-dependent models, 0.882 for temperature-dependent models, and 0.542 for elevationdependent models). These values are consistently above the $0.33(1 / 3)$ weight that would be expected if non-environment-dependent, temperature-dependent rate and elevation-dependent models models were equally likely.

\section{Discussion}

\subsection{Long-lived mountain building triggering both ancient and recent radiations}

We have studied potential drivers behind the diversification histories of six South American clades, four originating in the Late Cretaceous, and two during the latest Eocene-earliest Oligocene. We show that for Dendrobatidae, Hemiphractidae and Liolaemidae, the diversification history is likely primarily driven by environment-independent factors; for Centrolenidae, primarily by Cenozoic temperature variations, and for Aromobatidae and Leptodactylidae, primarily by Andean mountain building (Figs. 4 and 5). Interestingly, the two clades for which we link diversification to Andean elevation (Aromobatidae and Leptodactylidae) diversified faster during the incipient (Late Cretaceous Paleogene) phase of Andean orogeny. During this phase, the western margin of the South American continent transformed from a continental margin hosting a magmatic arc with localized topography only and average elevations below $1000 \mathrm{~m}$ (Vergara et al., 1995; Boekhout et al., 2012; Horton, 2018), into a fold-thrust belt with significant and continuous topography (Horton, 2018; Boschman, 2021; Fig. 1). During 

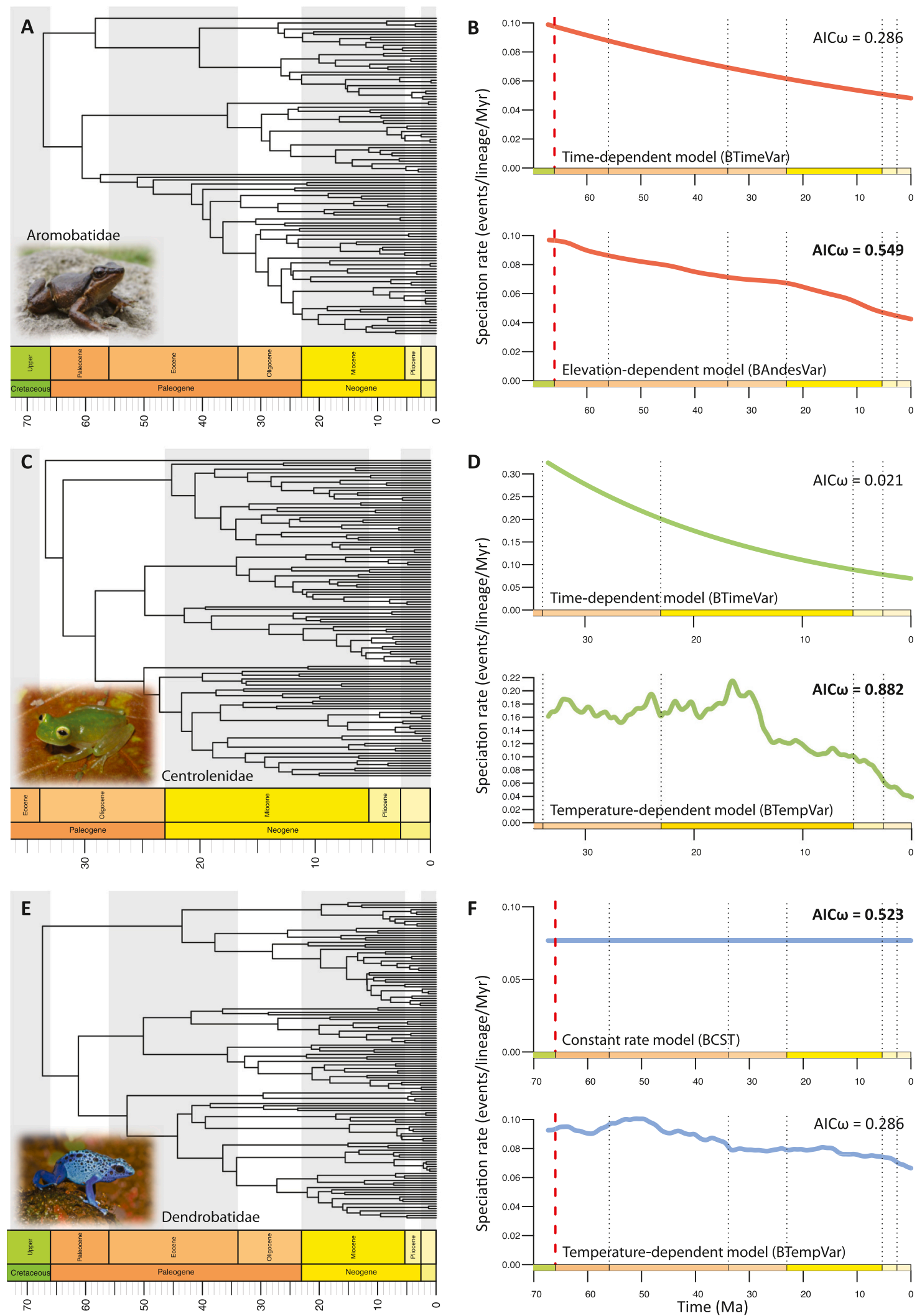

Fig. 5. Estimating the diversification processes for three Neotropical frog families distributed in the Andes. Left panels show the time-calibrated phylogenies for three Neotropical frog families: A) Aromobatidae (cryptic forest frogs), C) Centrolenidae (glass frogs), and E) Dendrobatidae (poison dart frogs); from Hutter et al. (2017). Right panels show, for each family, the results of the best environment-independent diversification model (top panel) and of the best environment-dependent diversification model (bottom panel). Akaike weights (AIC $\omega$ ) for both models are shown and the best-fit model for each family is indicated in bold. Pictured for Aromobatidae is Rheobates palmatus by G.A. Chaves Portilla, for Centrolenidae is Hyalinobatrachium fleischmanni by M. Rivera Correa, and for Dendrobatidae is Dendrobates tinctorius by $\mathrm{H}$. Zell. 
this time, the Andes were still significantly lower and less wide compared to their modern extent, but the first (arid) high-altitude habitats were appearing, especially in the southern (Mathiasen and Premoli, 2010) and central (Quade et al., 2015) Andes.

Aromobatidae and Leptodactylidae are both widely distributed in the Andes, but for both clades, the center of species richness is located outside of the Andes. Nonetheless, for Aromobatidae, diversification has previously been linked to early Miocene uplift of the Eastern Cordillera of Colombia and the resulting middle Miocene onset of aridity in the Magdalena Valley (Muñoz-Ortiz et al., 2015). Additionally, indirect effects of Andean uplift shaped river and lake system dynamics in western Amazonia, which acted as a source of aromobatid diversity for the rest of Amazonia (Vacher et al., 2017; Réjaud et al., 2020). With this study, we now add evidence for the influence of early Andean orogeny to Aromobatidae and Leptodactylidae diversification (Figs. 4B and 5D). This result is in line with results from Santos et al. (2009), who concluded that montane habitats in the Guiana Shield and Atlantic Forest regions were colonized at a later stage.

Although diversification of Liolaemidae is best explained by an increase of speciation towards the present without invoking the role of environment, the second best-fit model (almost equally strong; Fig. 5F) indicates a positive relation between speciation rates and elevation. This result is in line with the study of Esquerré et al. (2019), who concluded that uplift of the Andes promoted Liolaemidae diversification through allopatric fragmentation, and acted as a species pump for the surrounding regions.

Perhaps surprisingly, our analyses did not select the elevationdependent model as the best fit model for the hyloid frog clades Centrolenidae, Dendrobatidae and Hemiphractidae, contrary to previous conclusions reached concerning these groups (Hutter et al., 2017). For Centrolenidae, our analyses instead yielded strong support for the temperature-dependent model with high speciation rates during warm periods (Fig. 4D, F). This suggests a substantial effect of Cenozoic temperature variations in shaping Neotropical diversification in the Andes; a model that had so far not been tested. Alternatively, these results could be misleading, because the temperature-model has been shown to fit well overall across tetrapod families (Condamine et al., 2019a). Finally, the best model for Dendrobatidae and Hemiphractidae is a model with constant speciation rates through time. For the latter clade, this model could reflect true evolutionary mechanisms, because marsupial frogs are unique among anurans in that the eggs develop on the back or in dorsal pouches in the female (Castroviejo-Fisher et al., 2015). Females of Cryptobatrachus, Hemiphractus, and Stefania carry their eggs and young on their backs, and in other hemiphractids, the eggs develop in a closed pouch (Gastrotheca and some Flectonotus) or in an open pouch (other Flectonotus). This breeding behaviour could buffer rates of diversification because these species are independent of water sources; they avoid the eggs having to hatch in ponds and develop as free-swimming tadpoles, which is prone to predation, and relies on favorable environmental conditions.

The effect of Paleogene orogeny that we report differs from the conclusions of a wealth of studies finding recent and rapid mountain clade radiations across the world's mountain belts (e.g. Lenevue et al., 2009; Mao et al., 2010; Drummond et al., 2012; Jabbour and Renner, 2012; Wang et al., 2012; Schwery et al., 2015; Lagomarsino et al., 2016; Esquerré et al., 2019; Ye et al., 2019). These findings do not contradict ours, but rather, it shows that so far, ancient mountain radiations have largely been undetected. In the study of Andean radiations, two of the main reasons for the absence of ancient radiations are the focus on Neogene Neotropical clades, and in some cases, the misconception that the bulk of Andean topography is young. By incorporating the early history of mountain building, and selecting old (Late Cretaceous) clades, we demonstrate the potential effect of the initial emergence of highaltitude habitats on diversification. This implies that throughout the long-lived history of surface uplift in the Andes, mountain building drove the diversification of different clades at different times, while not affecting yet other clades altogether.

An analogy can be made with the history of uplift and diversification in the Tibetan Plateau region. Renner (2016) showed that many macroevolutionary and biogeographic studies have linked (potentially non-existent) recent uplift to young and rapid radiations (e.g. Favre et al., 2015, 2016; Ebersbach et al., 2017; Ye et al., 2019), despite geological evidence pointing to an Eocene $4 \mathrm{~km}$-high Tibetan Plateau. Although controversy about the uplift history of the Tibetan Plateau is not yet fully resolved (see e.g. Rowley and Garzione, 2007; Botsyun et al., 2019), both the synthesis of Renner (2016) and the current study illustrate the importance of accurate and detailed paleogeographic reconstructions that capture the complexity and heterogeneity of mountain building over geological time, and the importance of connecting geologists and biologists in the attempt to solve these interdisciplinary problems.

\subsection{Limitations of current modelling approaches and future perspectives}

Distinguishing between the drivers of diversification requires datasets that adequately sample large geographical and taxonomic scales through both long and short time intervals (e.g. Marx and Uhen, 2010; Eronen et al., 2015; Lagomarsino et al., 2016; Lehtonen et al., 2017; Condamine et al., 2018, Condamine et al., 2019a, 2019b). To unravel the processes governing the tempo and mode of lineage diversification, phylogenies are required that encompass at least $80 \%$ of the total standing diversity within the clade of interest (e.g. Cusimano and Renner, 2010; Höhna et al., 2011; Davis et al., 2013). This sampling ideally captures the entire range of ecological, geographic and morphological diversity, which requires accurate taxonomy, and clear documentation of the numbers of identifiable species in the region(s) of interest. As taxonomists remain underfunded, consensus on this basic information is not yet reached for all groups, yet is increasingly available for vertebrate groups. Knowledge of species ecology, including species interactions and species traits, may greatly enhance the design of macroevolutionary analyses in relation with hypotheses to test. Fortunately, phylogenies are increasingly improving, even in species-rich groups, and biological data, including morphology, ecology and distribution, are accumulating at an unprecedented rate (e.g. Pigot et al., 2020).

The state-of-the-art analytical framework used in this study is a step forward in our understanding of the diversification of lineages and its drivers, but is not without limitations. First, as with many macroevolutionary models, it suffers from the fundamental dilemma of extrapolation of correlations to causations. Second, difficulties remain in the estimation of speciation and extinction rates from phylogenies of extant species alone (e.g. Nee, 2006; Ricklefs, 2007; Rabosky and Lovette, 2008; Crisp and Cook, 2009; Quental and Marshall, 2010; Burin et al., 2019; Pannetier et al., 2021). For instance, simulation and empirical studies have shown that it is complicated to distinguish between decreasing speciation or increasing speciation when the net diversification rate declines through time (Rabosky and Lovette, 2008; Crisp and Cook, 2009). Furthermore, Burin et al. (2019) show that two popular methods perform equally well when varying speciation rates control decline, but when decline was only caused by an increase in extinction rates both methods wrongly assign the variation in net diversification to a drop in speciation. Several clades of our study show decay of speciation through time and no extinction (Figs. 5 and 6), and we thus remain cautious with these estimations. Recently, Pannetier et al. (2021) demonstrated that phylogenetic trees contain insufficient information to detect the presence or absence of diversity-dependent diversification, and we thus refrained ourselves to use this model although it can provide additional tests of macroevolutionary hypotheses on the role of within-clade species interactions compared to abiotic factors (Condamine et al., 2019a). Third, it remains challenging to decipher the direct drivers of speciation or extinction rates and events (Ezard et al., 2016), as environmental variables may be autocorrelated. For instance, paleoelevation per se may not be a direct driver of diversification, but rather, 

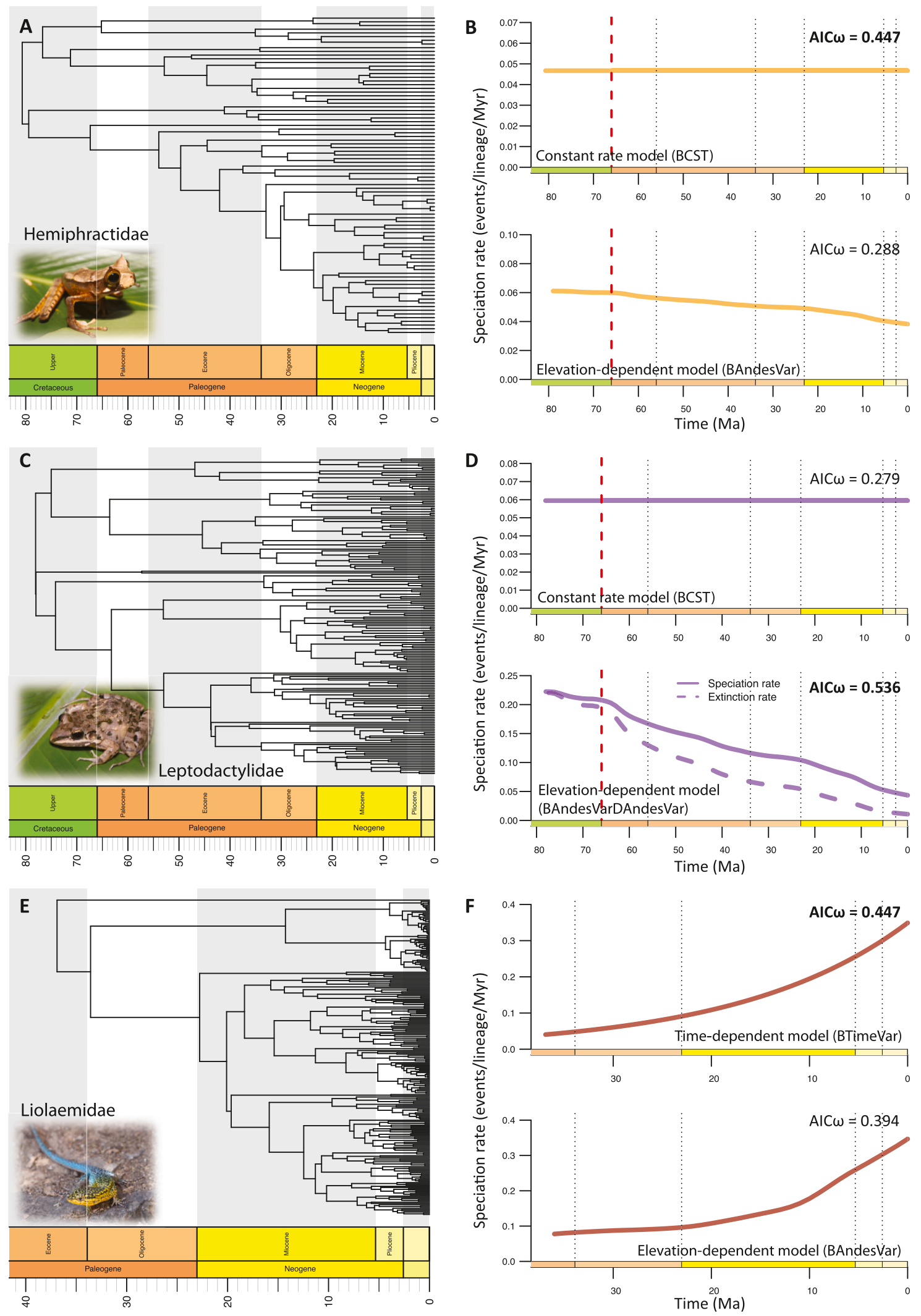

Fig. 6. Estimating the diversification processes for two Neotropical frog families and one Neotropical lizard family distributed in the Andes. Left panels show the time-calibrated phylogenies for three Neotropical frog families: A) Hemiphractidae (marsupial frogs), C) Leptodactylidae (southern frogs), and E) Liolaemidae (liolaemid lizards); from Hutter et al. (2017) and Esquerré et al. (2019). Right panels show, for each family, the results of the best environment-independent diversification model (top panel) and of the best environment-dependent diversification model (bottom panel). Leptodactylidae is the only clade for which extinction rates are estimated in the best-fit model, which are shown in panel D. Akaike weights (AIC $\omega$ ) for both models are shown and the best-fit model for each family is indicated in bold. Pictured for Hemiphractidae is Gastrotheca cornuta by B. Gratwicke, for Leptodactylidae is Leptodactylus fragilis by E. Alzate, and for Liolaemidae is Liolaemus tenuis by Kaldari. 
Table 3

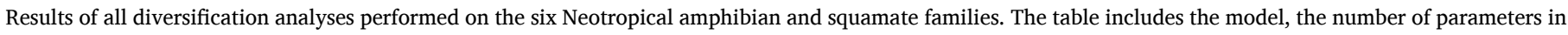

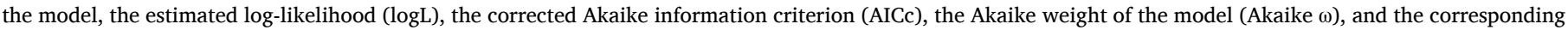

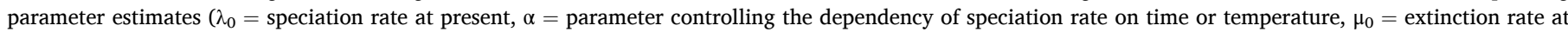

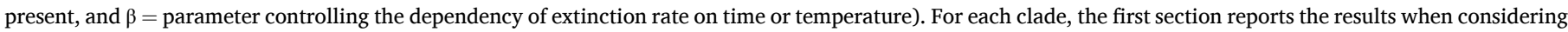

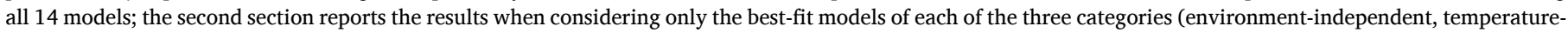
dependent, elevation-dependent), resulting in different Akaike weights. The best-fitting model is highlighted in bold.

\begin{tabular}{|c|c|c|c|c|c|c|c|c|c|}
\hline Family & Models & NP & $\log L$ & AICc & Akaike $\omega$ & $\lambda 0$ & $\alpha$ & $\mu 0$ & $\beta$ \\
\hline \multirow[t]{17}{*}{ Aromobatidae } & BCST & 1 & -452.378 & 906.79 & 0.108 & 0.0571 & - & - & - \\
\hline & BCSTDCST & 2 & -452.378 & 908.86 & 0.038 & 0.0571 & - & 0 & - \\
\hline & BTimeVar & 2 & -451.028 & 906.16 & 0.148 & 0.0481 & 0.0107 & - & - \\
\hline & BTimeVarDCST & 3 & -451.028 & 908.266 & 0.052 & 0.0481 & 0.0107 & 0 & - \\
\hline & BCSTDTimeVar & 3 & -452.378 & 910.966 & 0.013 & 0.0571 & - & 0 & $-9.00 \mathrm{E}-04$ \\
\hline & BTimeVarDTimeVar & 4 & -451.028 & 910.41 & 0.018 & 0.0481 & 0.0107 & 0 & 0.0121 \\
\hline & BTempVar & 2 & -451.581 & 907.266 & 0.085 & 0.0322 & 0.0344 & - & - \\
\hline & BTempVarDCST & 3 & -451.581 & 909.372 & 0.03 & 0.0323 & 0.0343 & 0 & - \\
\hline & BCSTDTempVar & 3 & -452.389 & 910.988 & 0.013 & 0.0571 & - & 0 & 0.0039 \\
\hline & BTempVarDTempVar & 4 & -451.581 & 911.515 & 0.01 & 0.0322 & 0.0343 & 0 & 0.0035 \\
\hline & BAndesVar & 2 & -450.377 & 904.858 & 0.283 & 0.1058 & $-6.00 \mathrm{E}-04$ & - & - \\
\hline & BAndesVarDCST & 3 & -450.377 & 906.964 & 0.099 & 0.1056 & $-6.00 \mathrm{E}-04$ & 0 & - \\
\hline & BCSTDAndesVar & 3 & -452.388 & 910.987 & 0.013 & 0.057 & - & 0.0234 & -0.0164 \\
\hline & BAndesVarDAndesVar & 4 & -449.392 & 907.139 & 0.091 & 0.2584 & -0.0014 & 0.4434 & -0.0034 \\
\hline & BTimeVar & 2 & -451.028 & 906.16 & 0.286 & 0.0481 & 0.0107 & - & - \\
\hline & BTempVar & 2 & -451.581 & 907.266 & 0.165 & 0.0322 & 0.0344 & - & - \\
\hline & BAndesVar & 2 & -450.377 & 904.858 & 0.549 & 0.1058 & $-6.00 \mathrm{E}-04$ & - & - \\
\hline \multirow[t]{17}{*}{ Centrolenidae } & BCST & 1 & -423.266 & 848.563 & 0 & 0.1048 & - & - & - \\
\hline & BCSTDCST & 2 & -423.266 & 850.627 & 0 & 0.1048 & - & 0 & - \\
\hline & BTimeVar & 2 & -416.061 & 836.218 & 0.015 & 0.0695 & 0.0462 & - & - \\
\hline & BTimeVarDCST & 3 & -416.061 & 838.315 & 0.005 & 0.0695 & 0.0462 & 0 & - \\
\hline & BCSTDTimeVar & 3 & -423.266 & 852.725 & 0 & 0.1048 & - & 0 & 0.0071 \\
\hline & BTimeVarDTimeVar & 4 & -416.061 & 840.447 & 0.002 & 0.0695 & 0.0462 & 0 & -0.0026 \\
\hline & BTempVar & 2 & -412.34 & 828.776 & 0.6 & 0.0048 & 0.2013 & - & - \\
\hline & BTempVarDCST & 3 & -412.34 & 830.873 & 0.21 & 0.0048 & 0.2013 & 0 & - \\
\hline & BCSTDTempVar & 3 & -423.291 & 852.776 & 0 & 0.1048 & - & 0 & 0.0029 \\
\hline & BTempVarDTempVar & 4 & -412.34 & 833.005 & 0.072 & 0.0048 & 0.2013 & 0 & 0.0093 \\
\hline & BAndesVar & 2 & -414.555 & 833.205 & 0.065 & 0.8051 & -0.0018 & - & - \\
\hline & BAndesVarDCST & 3 & -414.555 & 835.304 & 0.023 & 0.8184 & -0.0018 & 0 & - \\
\hline & BCSTDAndesVar & 3 & -423.291 & 852.776 & 0 & 0.1047 & - & 0.0157 & -0.0141 \\
\hline & BAndesVarDAndesVar & 4 & -414.554 & 837.433 & 0.008 & 0.8039 & -0.0018 & 0.0027 & -0.0034 \\
\hline & BTimeVar & 2 & -416.061 & 836.218 & 0.021 & 0.0695 & 0.0462 & - & - \\
\hline & BTempVar & 2 & -412.34 & 828.776 & 0.882 & 0.0048 & 0.2013 & - & - \\
\hline & BAndesVar & 2 & -414.555 & 833.205 & 0.096 & 0.8051 & -0.0018 & - & - \\
\hline \multirow[t]{17}{*}{ Dendrobatidae } & BCST & 1 & -502.194 & 1006.417 & 0.26 & 0.0767 & - & - & - \\
\hline & BCSTDCST & 2 & -502.194 & 1008.478 & 0.093 & 0.0767 & - & 0 & - \\
\hline & BTimeVar & 2 & -502.168 & 1008.427 & 0.095 & 0.0782 & -0.0014 & - & - \\
\hline & BTimeVarDCST & 3 & -502.169 & 1010.519 & 0.033 & 0.0784 & -0.0015 & 0 & - \\
\hline & BCSTDTimeVar & 3 & -502.194 & 1010.569 & 0.033 & 0.0767 & - & 0 & 0.009 \\
\hline & BTimeVarDTimeVar & 4 & -502.168 & 1012.642 & 0.012 & 0.0783 & -0.0014 & 0 & 0.025 \\
\hline & BTempVar & 2 & -501.767 & 1007.624 & 0.142 & 0.0521 & 0.0237 & - & - \\
\hline & BTempVarDCST & 3 & -501.767 & 1009.716 & 0.05 & 0.0522 & 0.0236 & 0 & - \\
\hline & BCSTDTempVar & 3 & -502.208 & 1010.599 & 0.032 & 0.0767 & - & 0 & 0.0067 \\
\hline & BTempVarDTempVar & 4 & -501.767 & 1011.839 & 0.017 & 0.0521 & 0.0237 & 0 & 0.0032 \\
\hline & BAndesVar & 2 & -502.172 & 1008.434 & 0.095 & 0.083 & $-1.00 \mathrm{E}-04$ & - & - \\
\hline & BAndesVarDCST & 3 & -502.172 & 1010.525 & 0.033 & 0.083 & $-1.00 \mathrm{E}-04$ & 0 & - \\
\hline & BCSTDAndesVar & 3 & -501.739 & 1009.659 & 0.051 & 0.0776 & - & 1.6505 & -0.0108 \\
\hline & BAndesVarDAndesVar & 4 & -500.644 & 1009.593 & 0.053 & 0.1848 & $-7.00 \mathrm{E}-04$ & 0.427 & -0.0032 \\
\hline & BCST & 1 & -502.194 & 1006.417 & 0.523 & 0.0767 & - & - & - \\
\hline & BTempVar & 2 & -501.767 & 1007.624 & 0.286 & 0.0521 & 0.0237 & - & - \\
\hline & BAndesVar & 2 & -502.172 & 1008.434 & 0.191 & 0.083 & $-1.00 \mathrm{E}-04$ & - & - \\
\hline \multirow[t]{12}{*}{ Hemiphractidae } & BCST & 1 & -354.164 & 710.375 & 0.231 & 0.0467 & - & - & - \\
\hline & BCSTDCST & 2 & -354.164 & 712.472 & 0.081 & 0.0467 & - & 0 & - \\
\hline & BTimeVar & 2 & -353.837 & 711.819 & 0.112 & 0.0423 & 0.0046 & - & - \\
\hline & BTimeVarDCST & 3 & -353.837 & 713.967 & 0.038 & 0.0423 & 0.0046 & 0 & - \\
\hline & BCSTDTimeVar & 3 & -354.164 & 714.62 & 0.028 & 0.0467 & - & 0 & 0.0023 \\
\hline & BTimeVarDTimeVar & 4 & -353.777 & 716.049 & 0.014 & 0.0409 & 0.0099 & 0.0029 & 0.0384 \\
\hline & BTempVar & 2 & -353.641 & 711.427 & 0.136 & 0.0287 & 0.0272 & - & - \\
\hline & BTempVarDCST & 3 & -353.641 & 713.576 & 0.047 & 0.0288 & 0.0272 & 0 & - \\
\hline & BCSTDTempVar & 3 & -354.169 & 714.631 & 0.027 & 0.0467 & - & 0 & 0.0013 \\
\hline & BTempVarDTempVar & 4 & -353.641 & 715.777 & 0.015 & 0.0286 & 0.0274 & 0 & 0.0106 \\
\hline & BAndesVar & 2 & -353.555 & 711.256 & 0.148 & 0.0628 & $-3.00 \mathrm{E}-04$ & - & - \\
\hline & BAndesVarDCST & 3 & -353.555 & 713.404 & 0.051 & 0.0628 & $-3.00 \mathrm{E}-04$ & 0 & - \\
\hline
\end{tabular}


Table 3 (continued)

\begin{tabular}{|c|c|c|c|c|c|c|c|c|c|}
\hline Family & Models & NP & $\log L$ & AICc & Akaike $\omega$ & $\lambda 0$ & $\alpha$ & $\mu 0$ & $\boldsymbol{\beta}$ \\
\hline & BCSTDAndesVar & 3 & -354.169 & 714.631 & 0.027 & 0.0467 & - & 0 & -0.018 \\
\hline & BAndesVarDAndesVar & 4 & -352.585 & 713.663 & 0.045 & 0.962 & -0.0025 & 0.8961 & -0.0025 \\
\hline & BCST & 1 & -354.164 & 710.375 & 0.447 & 0.0467 & - & - & - \\
\hline & BTempVar & 2 & -353.641 & 711.427 & 0.264 & 0.0287 & 0.0272 & - & - \\
\hline & BAndesVar & 2 & -353.555 & 711.256 & 0.288 & 0.0628 & $-3.00 \mathrm{E}-04$ & - & - \\
\hline \multirow[t]{17}{*}{ Leptodactylidae } & BCST & 1 & -719.741 & 1441.504 & 0.136 & 0.0595 & - & - & - \\
\hline & BCSTDCST & 2 & -719.741 & 1443.547 & 0.049 & 0.0595 & - & 0 & - \\
\hline & BTimeVar & 2 & -719.405 & 1442.875 & 0.069 & 0.0559 & 0.0037 & - & - \\
\hline & BTimeVarDCST & 3 & -719.405 & 1444.941 & 0.024 & 0.0559 & 0.0037 & 0 & - \\
\hline & BCSTDTimeVar & 3 & -719.741 & 1445.614 & 0.017 & 0.0595 & - & 0 & 0.0045 \\
\hline & BTimeVarDTimeVar & 4 & -718.905 & 1446.032 & 0.014 & 0.0531 & 0.0126 & 0.0045 & 0.0458 \\
\hline & BTempVar & 2 & -719.13 & 1442.325 & 0.09 & 0.0409 & 0.0223 & - & - \\
\hline & BTempVarDCST & 3 & -719.13 & 1444.392 & 0.032 & 0.0409 & 0.0223 & 0 & - \\
\hline & BCSTDTempVar & 3 & -719.758 & 1445.648 & 0.017 & 0.0595 & - & 0 & 0.0035 \\
\hline & BTempVarDTempVar & 4 & -719.13 & 1446.481 & 0.011 & 0.0406 & 0.0226 & 0 & 0.0037 \\
\hline & BAndesVar & 2 & -718.379 & 1440.824 & 0.192 & 0.0862 & $-3.00 \mathrm{E}-04$ & - & - \\
\hline & BAndesVarDCST & 3 & -718.38 & 1442.891 & 0.068 & 0.0858 & $-3.00 \mathrm{E}-04$ & 0 & - \\
\hline & BCSTDAndesVar & 3 & -719.758 & 1445.648 & 0.017 & 0.0594 & - & 0.0259 & -0.0483 \\
\hline & BAndesVarDAndesVar & 4 & -715.988 & 1440.198 & 0.262 & 0.2697 & -0.001 & 0.3149 & -0.0018 \\
\hline & BCST & 1 & -719.741 & 1441.504 & 0.279 & 0.0595 & - & - & - \\
\hline & BTempVar & 2 & -719.13 & 1442.325 & 0.185 & 0.0409 & 0.0223 & - & - \\
\hline & BAndesVarDAndesVar & 4 & -715.988 & 1440.198 & 0.536 & 0.2697 & -0.001 & 0.3149 & -0.0018 \\
\hline \multirow[t]{17}{*}{ Liolaemidae } & BCST & 1 & -621.766 & 1245.548 & 0 & 0.2688 & - & - & - \\
\hline & BCSTDCST & 2 & -615.241 & 1234.528 & 0.001 & 0.3906 & - & 0.2144 & - \\
\hline & BTimeVar & 2 & -609.906 & 1223.859 & 0.262 & 0.3491 & -0.0584 & - & - \\
\hline & BTimeVarDCST & 3 & -609.906 & 1225.906 & 0.094 & 0.3491 & -0.0583 & 0 & - \\
\hline & BCSTDTimeVar & 3 & -610.665 & 1227.424 & 0.044 & 0.3571 & - & 0.1126 & 0.0484 \\
\hline & BTimeVarDTimeVar & 4 & -609.856 & 1227.87 & 0.035 & 0.3464 & -0.0521 & 0.0048 & 0.0828 \\
\hline & BTempVar & 2 & -614.593 & 1233.234 & 0.002 & 1.0754 & -0.1036 & - & - \\
\hline & BTempVarDCST & 3 & -614.175 & 1234.445 & 0.001 & 0.7288 & -0.062 & 0.0886 & - \\
\hline & BCSTDTempVar & 3 & -609.916 & 1225.926 & 0.093 & 0.3293 & - & 0.001 & 0.3225 \\
\hline & BTempVarDTempVar & 4 & -610.042 & 1228.242 & 0.029 & 0.3857 & -0.0143 & 7.00E-04 & 0.3379 \\
\hline & BAndesVar & 2 & -610.034 & 1224.115 & 0.231 & 0.0226 & 0.0011 & - & - \\
\hline & BAndesVarDCST & 3 & -610.034 & 1226.162 & 0.083 & 0.0226 & 0.0011 & 0 & - \\
\hline & BCSTDAndesVar & 3 & -610.131 & 1226.357 & 0.075 & 0.3473 & - & 1.6151 & -0.0012 \\
\hline & BAndesVarDAndesVar & 4 & -609.576 & 1227.311 & 0.047 & 0.0583 & $7.00 \mathrm{E}-04$ & 1.2505 & -0.0019 \\
\hline & BTimeVar & 2 & -609.906 & 1223.859 & 0.447 & 0.3491 & -0.0584 & - & - \\
\hline & BCSTDTempVar & 3 & -609.916 & 1225.926 & 0.159 & 0.3293 & - & 0.001 & 0.3225 \\
\hline & BAndesVar & 2 & -610.034 & 1224.115 & 0.394 & 0.0226 & 0.0011 & - & - \\
\hline
\end{tabular}

the many indirect consequences of uplift, such as habitat fragmentation or local climate change (Lagomarsino et al., 2016; Pérez-Escobar et al., 2017b; Nevado et al., 2018). Furthermore, we here compare environment-independent, temperature-dependent and elevationdependent birth-death models, but temperature and elevation are not the only possible drivers of diversification, as many other a(biotic) processes (e.g. regional sea level variations, precipitation, erosion, interactions between species) may have played a role. However, compared to paleoelevation and global paleotemperature, quantifying or reconstructing these other possible drivers of diversification is a much bigger challenge, which hampers testing them in diversification models. In addition, it is questionable whether it truly is elevation (or temperature) that is driving diversification, rather than the change in elevation (or temperature). Although biological interpretation might become less straightforward, future studies might consider incorporating environmental-change diversification models, using the time-derivative of environmental variables.

To uncover the extent to which speciation and extinction vary and according to which drivers, macroevolutionary studies may need to combine diversification (birth-death) models with parametric biogeography models (Ree and Smith, 2008; Quintero et al., 2015) or mechanistic eco-evolutionary simulation models (Rangel et al., 2018; Hagen et al., 2021). Such combined approaches can for example be used to estimate whether speciation occurred via allopatry (vicariance) or sympatry (ecological speciation), which specific factors in paleo- environmental change caused speciation and/or extinction, and in which locations these diversification events took place. It is worth mentioning that some models exist to test the role of diversitydependence in the context of allopatry (Pigot et al., 2010; Valente et al., 2015).

New developments in the field of trait-dependent models form a second line of research contributing to our understanding of the interactions between biotic and abiotic factors and their effects on diversity dynamics (Maddison et al., 2007; Goldberg et al., 2011; Beaulieu and O'Meara, 2016). Cantalapiedra et al. (2014) developed a climatebased trait-dependent diversification model, in which rates of speciation not only vary as a function of the same global temperature curve that we incorporated into our analysis, but also among traits. The model is thereby able to identify differences in diversification history between clades with different functional traits as a function of changes in environment. Cantalapiedra et al. (2014) showed that ruminant clades with three feeding modes (browsers, grazers and mixed feeders) diversified differently during warm or cold periods.

A remaining, outstanding question is which role competition plays in ecologically similar clades that are phylogenetically unrelated (Benton, 1987; Hembry and Weber, 2020). Although it is difficult to model the effect of external clades interacting with the focal clade and their effects on speciation and/or extinction with current models, some progress has been made with fossil-based models showing that clade competition occurred over long timescales (Liow et al., 2015; Silvestro et al., 2015). 
It is thus possible to assess the effect of competition on diversification, in which speciation and extinction rates are correlated with the diversity trajectory of another clade. Under competitive interaction scenarios, increasing species diversity has the effect of suppressing speciation rates and/or increasing extinction rates. Although in phylogenetic studies, diversity dependence is typically tested within a single clade (Etienne et al., 2012), our phylogeny-based diversification model can be extended to allow for competition among species that are not closely related, but share similar ecological niches (Condamine et al., 2020).

Lastly, studying the effects of environmental (i.e. climatic or geological) change requires accurate reconstructions of these changes through time. Despite the existence of contrasting datasets and resulting controversy, there is a relative abundance of data on the history of uplift of the two highest, largest (and most biodiverse) mountain belts on Earth: the Andes (see compilation in Boschman, 2021) and the Tibetan Plateau-Himalayas-Hengduan mountains (e.g. An et al., 2001; Rowley and Garzione, 2007; Botsyun et al., 2019), and to a lesser extent, of the North American Cordillera (e.g. Chamberlain et al., 2012). As a result, the majority of studies on environment-dependent diversification have focussed on these regions (Lagomarsino et al., 2016; Pérez-Escobar et al., 2017b; Esquerré et al., 2019; Testo et al., 2019; Ding et al., 2020). Working towards a global understanding of the relationship between environmental change and lineage diversification (Antonelli et al., 2018a; Quintero and Jetz, 2018; Rahbek et al., 2019a, 2019b) calls for the collection of paleoelevation data on lesser-studied smaller orogens, particularly in species rich regions, such as for example New Guinea, hosting the world's richest island flora (Cámara-Leret et al., 2020).

In conclusion, we still face important limitations in data availability as well as methodological shortcomings, but by acknowledging them we can target where to focus future efforts of the geological, macroevolutionary and biogeographical communities. Together, we may gain a better understanding of how environmental and biotic triggers are intertwined and of the rich, deep past of Earth's biological diversity. We hope that our approach (and analytical framework) will help the forward movement in that direction, and that it will provide perspectives for future investigations on other model groups, and in other regions.

\section{Conclusions}

Analyzing the role of paleogeographic and paleoclimatic history in species diversification through macroevolutionary analyses has never been more exciting and promising than today. The conjunction of rapid and massive increases in the availability of biological datasets (phylogenies, fossils, georeferenced occurrences and ecological traits) and paleoclimate and paleogeographic reconstructions on the one hand, and the successful development of powerful analytical tools on the other, now enables assessing the relative roles of climate change and mountain building on lineage diversification.

Here, we analysed the diversification history of six Neotropical frog and lizard families in light of Cenozoic climate variations and Andean mountain building. The recent (Neogene) rise of the Andes is often considered as the prime driver of biological diversification in the Neotropics, but here we unveil a more complex evolutionary history for ancient yet species-rich frog and lizard families. We find clade-specific responses to temperature and elevation, and conclude that throughout the long-lived history of surface uplift in the Andes, mountain building drove the diversification of different clades at different times, while not directly affecting other clades. Although we find that the diversification of Aromobatidae and Leptodactylidae was influenced by the rise of Andes, we conclude that this effect played a role in the Late CretaceousPaleogene phase of orogeny, much earlier than previously proposed (i.e. Neogene). Moreover, we demonstrate that other drivers must be considered when studying mountain clade radiations: diversification rates of Centrolenidae were high during the warmer periods of the Cenozoic. Additionally, even a strict Andean-endemic lizard radiation shows mixed evidence for a direct role of Andean uplift driving the diversification. Therefore, our study argues that pre-Neogene environmental changes, either triggered by Andean uplift or resulting from global climate variations, should not be dismissed as drivers of Neotropical diversification, and calls for a greater appreciation of the ancient Andean paleo-elevation history in the build-up of species on the Earth's most biodiverse continent.

\section{Data availability}

All data files (phylogenies, environmental variables) and scripts necessary to perform the analyses are available via the online repository Figshare: https://doi.org/10.6084/m9.figshare.13369298.

\section{Declaration of Competing Interest}

The authors declare that they have no known competing financial interests or personal relationships that could have appeared to influence the work reported in this paper.

\section{Acknowledgements}

This work was funded by ETH postdoctoral fellowship 18-2 FEL-52, and by an "Investissements d'Avenir" grant managed by the Agence Nationale de la Recherche (CEBA, ref. ANR-10-LABX-25-01) and the ANR GAARAnti project (ANR-17-CE31-0009). We thank editor Daniele Silvestro, Pierre Sepulchre and an anonymous reviewer for very detailed and constructive comments, and Carina Hoorn for setting up this collaboration and the invitation to submit to this special issue.

\section{Appendix A. Supplementary data}

Supplementary data to this article can be found online at https://doi. org/10.1016/j.gloplacha.2021.103704.

\section{References}

Amante, C., Eakins, B.W., 2009. ETOPO1 arc-minute global relief model: Procedures, data sources and analysis. In: NOAA National Centers for Environmental Information.

An, Z., Kutzbach, J.E., Prell, W.L., Porter, S.C., 2001. Evolution of Asian monsoons and phased uplift of the Himalaya-Tibetan plateau since Late Miocene times. Nature 411 (6833), 62-66.

Anderson, V.J., Saylor, J.E., Shanahan, T.M., Horton, B.K., 2015. Paleoelevation records from lipid biomarkers: application to the tropical Andes. Geol. Soc. Am. Bull. 127 (11-12), 1604-1616.

Anderson, V.J., Horton, B.K., Saylor, J.E., Mora, A., Tesón, E., Breecker, D.O., Ketcham, R.A., 2016. Andean topographic growth and basement uplift in southern Colombia: implications for the evolution of the Magdalena, Orinoco, and Amazon river systems. Geosphere 12 (4), 1235-1256.

Antonelli, A., Sanmartín, I., 2011. Why are there so many plant species in the Neotropics? Taxon 60 (2), 403-414.

Antonelli, A., Nylander, J.A., Persson, C., Sanmartín, I., 2009. Tracing the impact of the Andean uplift on Neotropical plant evolution. Proc. Natl. Acad. Sci. 106 (24), 9749-9754.

Antonelli, A., Kissling, W.D., Flantua, S.G.A., Bermúdez, M.A., Mulch, A., MuellnerRiehl, A.N., Kreft, H., Linder, H.P., Badgley, C., Fjeldså, J., Fritz, S.A., Rahbek, C., Herman, F., Hooghiemstra, H., Hoorn, C., 2018a. Geological and climatic influences on mountain biodiversity. Nat. Geosci. 11 (10), 718-725. https://doi.org/10.1038/ s41561-018-0236-z.

Antonelli, A., Zizka, A., Carvalho, F.A., Scharn, R., Bacon, C.D., Silvestro, D., Condamine, F.L., 2018b. Amazonia is the primary source of neotropical biodiversity, Proc. Natl. Acad. Sci. 115 (23), 6034-6039.

Armijo, R., Lacassin, R., Coudurier-Curveur, A., Carrizo, D., 2015. Coupled tectonic evolution of Andean orogeny and global climate. Earth Sci. Rev. 143, 1-35.

Beaulieu, J.M., O'Meara, B.C., 2016. Detecting hidden diversification shifts in models of trait-dependent speciation and extinction. Syst. Biol. 65 (4), 583-601.

Benton, M.J., 1987. Progress and competition in macroevolution. Biol. Rev. 62 (3), 305-338.

Bermúdez, M., Hoorn, C., Bernet, M., Carrillo, E., Van Der Beek, P., Garver, J., Mora, J., Mehrkian, K., 2017. The detrital record of late-Miocene to Pliocene surface uplift and exhumation of the Venezuelan Andes in the Maracaibo and Barinas foreland basins. Basin Res. 29, 370-395.

Bershaw, J., Garzione, C.N., Higgins, P., MacFadden, B.J., Anaya, F., Alvarenga, H., 2010. Spatial-temporal changes in Andean plateau climate and elevation from stable isotopes of mammal teeth. Earth Planet. Sci. Lett. 289 (3-4), 530-538. 
Blisniuk, P.M., Stern, L.A., 2005. Stable isotope paleoaltimetry: a critical review. Am. J. Sci. 305 (10), 1033-1074.

Blisniuk, P.M., Stern, L.A., Chamberlain, C.P., Idleman, B., Zeitler, P.K., 2005. Climatic and ecologic changes during Miocene surface uplift in the Southern Patagonian Andes. Earth Planet. Sci. Lett. 230 (1), 125-142. http://www.sciencedirect.com/sci ence/article/pii/S0012821X04006971.

Blisniuk, P.M., Stern, L.A., Chamberlain, C.P., Zeitler, P.K., Ramos, V.A., Sobel, E.R., Haschke, M., Strecker, M.R., Warkus, F., 2006. Links between mountain uplift, climate, and surface processes in the southern Patagonian Andes. In: The Andes. Springer, pp. 429-440.

Boekhout, F., Spikings, R., Sempere, T., Chiaradia, M., Ulianov, A., Schaltegger, U., 2012 Mesozoic arc magmatism along the southern Peruvian margin during Gondwana breakup and dispersal. Lithos 146, 48-64.

Boschman, L.M., 2021. Andean mountain building since the Late Cretaceous: a paleoelevation reconstruction. Earth Sci. Rev. https://doi.org/10.1016/j. earscirev.2021.103640, 103640

Botsyun, S., Sepulchre, P., Donnadieu, Y., Risi, C., Licht, A., Rugenstein, J.K.C., 2019. Revised paleoaltimetry data show low Tibetan Plateau elevation during the Eocene. Science 363 (6430), eaaq1436.

Botsyun, S., Ehlers, T., Mutz, S., Methner, K., Krsnik, E., Mulch, A., 2020. Opportunities and challenges for paleoaltimetry in "small" orogens: insights from the European Alps. Geophys. Res. Lett. 47 (4) e2019GL086046.

Bruhn, R.L., Dalziel, I.W., 1977. Destruction of the Early Cretaceous marginal basin in the Andes of Tierra del Fuego. Island Arcs. Deep Sea Trenches and Back-Arc Basins 1, 395-405.

Brumfield, R.T., Edwards, S.V., 2007. Evolution into and out of the Andes: a Bayesian analysis of historical diversification in Thamnophilus antshrikes. Evolution 61 (2), 346-367.

Burin, G., Alencar, L.R., Chang, J., Alfaro, M.E., Quental, T.B., 2019. How well can we estimate diversity dynamics for clades in diversity decline? Syst. Biol. 68 (1), 47-62.

Burnham, D., Anderson, K., 2002. Model Selection and Multimodel Inference: A Practical Information-Theoretic Approach. Springer, New York.

Cámara-Leret, R., Frodin, D.G., Adema, F., Anderson, C., Appelhans, M.S., Argent, G. Guerrero, S.A., Ashton, P., Baker, W.J., Barfod, A.S., 2020. New Guinea has the world's richest island flora. Nature 584 (7822), 579-583.

Canavan, R.R., Carrapa, B., Clementz, M.T., Quade, J., DeCelles, P.G., Schoenbohm, L.M., 2014. Early Cenozoic uplift of the Puna Plateau, Central Andes, based on stable isotope paleoaltimetry of hydrated volcanic glass. Geology 42 (5), 447-450.

Cantalapiedra, J.L., FitzJohn, R.G., Kuhn, T.S., Fernández, M.H., DeMiguel, D., Azanza, B., Morales, J., Mooers, A.Ø., 2014. Dietary innovations spurred the diversification of ruminants during the Caenozoic. Proc. R. Soc. B Biol. Sci. 281 (1776), 20132746.

Carrapa, B., Strecker, M.R., Sobel, E.R., 2006. Cenozoic orogenic growth in the Central Andes: evidence from sedimentary rock provenance and apatite fission track thermochronology in the Fiambalá Basin, southernmost Puna Plateau margin (NW Argentina). Earth Planet. Sci. Lett. 247 (1-2), 82-100.

Carrapa, B., Huntington, K.W., Clementz, M., Quade, J., Bywater-Reyes, S., Schoenbohm, L.M., Canavan, R.R., 2014. Uplift of the Central Andes of NW Argentina associated with upper crustal shortening, revealed by multiproxy isotopic analyses. Tectonics 33 (6), 1039-1054.

Castroviejo-Fisher, S., De La Riva, I., Pombal Jr., J.P., da Silva, H.R., Rojas-Runjaic, F.J., Medina-Méndez, E., Frost, D.R., 2015. Phylogenetic systematics of egg-brooding frogs (Anura: Hemiphractidae) and the evolution of direct development. Zootaxa 4004 (1), 1-75.

Chamberlain, C., Poage, M., Craw, D., Reynolds, R., 1999. Topographic development of the Southern Alps recorded by the isotopic composition of authigenic clay minerals, South Island, New Zealand. Chem. Geol. 155 (3-4), 279-294.

Chamberlain, C.P., Mix, H.T., Mulch, A., Hren, M.T., Kent-Corson, M.L., Davis, S.J., Horton, T.W., Graham, S.A., 2012. The Cenozoic climatic and topographic evolution of the western North American Cordillera. Am. J. Sci. 312 (2), 213-262.

Chazot, N., Willmott, K.R., Condamine, F.L., De-Silva, D.L., Freitas, A.V., Lamas, G., Morlon, H., Giraldo, C.E., Jiggins, C.D., Joron, M., 2016. Into the Andes: multiple independent colonizations drive montane diversity in the Neotropical clearwing butterflies Godyridina. Mol. Ecol. 25 (22), 5765-5784.

Chazot, N., Willmott, K.R., Lamas, G., Freitas, A.V., Piron-Prunier, F., Arias, C.F., Mallet, J., De-Silva, D.L., Elias, M., 2019. Renewed diversification following Miocene landscape turnover in a Neotropical butterfly radiation. Glob. Ecol. Biogeogr. 28 (8), $1118-1132$

Colwyn, D.A., Brandon, M.T., Hren, M.T., Hourigan, J., Pacini, A., Cosgrove, M.G. Midzik, M., Garreaud, R.D., Metzger, C., 2019. Growth and steady state of the Patagonian Andes. Am. J. Sci. 319 (6), 431-472.

Condamine, F.L., Rolland, J., Morlon, H., 2013. Macroevolutionary perspectives to environmental change. Ecol. Lett. 16, 72-85.

Condamine, F.L., Toussaint, E.F., Clamens, A.-L., Genson, G., Sperling, F.A., Kergoat, G. J., 2015. Deciphering the evolution of birdwing butterflies 150 years after Alfred Russel Wallace. Sci. Rep. 5 (11860), 1-11.

Condamine, F.L., Rolland, J., Höhna, S., Sperling, F.A., Sanmartín, I., 2018. Testing the role of the Red Queen and Court Jester as drivers of the macroevolution of Apollo butterflies. Syst. Biol. 67 (6), 940-964.

Condamine, F.L., Rolland, J., Morlon, H., 2019a. Assessing the causes of diversification slowdowns: temperature-dependent and diversity-dependent models receive equivalent support. Ecol. Lett. 22 (11), 1900-1912.

Condamine, F.L., Romieu, J., Guinot, G., 2019b. Climate cooling and clade competition likely drove the decline of lamniform sharks. Proc. Natl. Acad. Sci. 116 (41), 20584-20590.
Condamine, F.L., Silvestro, D., Koppelhus, E.B., Antonelli, A., 2020. The rise of angiosperms pushed conifers to decline during global cooling. Proc. Natl. Acad. Sci. 117 (46), 28867-28875.

Cortés, A.J., Garzón, L.N., Valencia, J.B., Madriñán, S., 2018. On the causes of rapid diversification in the páramos: isolation by ecology and genomic divergence in espeletia. Front. Plant Sci. 9, 1700.

Cramer, B., Miller, K., Barrett, P., Wright, J., 2011. Late Cretaceous-Neogene trends in deep ocean temperature and continental ice volume: reconciling records of benthic foraminiferal geochemistry ( 8180 and $\mathrm{Mg} / \mathrm{Ca}$ ) with sea level history. J. Geophys. Res. Oceans 116 (C12).

Crisp, M.D., Cook, L.G., 2009. Explosive radiation or cryptic mass extinction? Interpreting signatures in molecular phylogenies. Evolution 63 (9), 2257-2265.

Cuesta, F., Muriel, P., Llambí, L.D., Halloy, S., Aguirre, N., Beck, S., Carilla, J., Meneses, R.I., Cuello, S., Grau, A., 2017. Latitudinal and altitudinal patterns of plant community diversity on mountain summits across the tropical Andes. Ecography 40 (12), 1381-1394.

Cusimano, N., Renner, S.S., 2010. Slowdowns in diversification rates from real phylogenies may not be real. Syst. Biol. 59 (4), 458-464.

Dalziel, I.W., De Wit, M.J., Palmer, K.F., 1974. Fossil marginal basin in the southern Andes. Nature 250 (5464), 291-294.

Davis, D., Suppe, J., Dahlen, F., 1983. Mechanics of fold-and-thrust belts and accretionary wedges. J. Geophys. Res. Solid Earth 88 (B2), 1153-1172.

Davis, M.P., Midford, P.E., Maddison, W., 2013. Exploring power and paramete estimation of the BiSSE method for analyzing species diversification. BMC Evol. Biol. 13 (1), 38.

Davis, K.E., Hill, J., Astrop, T.I., Wills, M.A., 2016. Global cooling as a driver of diversification in a major marine clade. Nat. Commun. 7 (1), 13003. https://doi.org/ 10.1038/ncomms13003.

Delsuc, F., Vizcaíno, S.F., Douzery, E.J., 2004. Influence of Tertiary paleoenvironmental changes on the diversification of South American mammals: a relaxed molecular clock study within xenarthrans. BMC Evol. Biol. 4 (1), 11.

Ding, W.-N., Ree, R.H., Spicer, R.A., Xing, Y.-W., 2020. Ancient orogenic and monsoondriven assembly of the world's richest temperate alpine flora. Science 369 (6503), $578-581$.

Drummond, C.S., Eastwood, R.J., Miotto, S.T., Hughes, C.E., 2012. Multiple continental radiations and correlates of diversification in Lupinus (Leguminosae): testing for key innovation with incomplete taxon sampling. Syst. Biol. 61 (3), 443-460.

Ebersbach, J., Schnitzler, J., Favre, A., Muellner-Riehl, A., 2017. Evolutionary radiations in the species-rich mountain genus Saxifraga L. BMC Evol. Biol. 17 (1), 119.

Egan, A.N., Crandall, K.A., 2008. Divergence and diversification in North American Psoraleeae (Fabaceae) due to climate change. BMC Biol. 6 (1), 55. https://doi.org/ 10.1186/1741-7007-6-55.

Eronen, J.T., Janis, C.M., Chamberlain, C.P., Mulch, A., 2015. Mountain uplift explains differences in Palaeogene patterns of mammalian evolution and extinction between North America and Europe. Proc. R. Soc. B Biol. Sci. 282 (1809), 20150136.

Erwin, D.H., 2009. Climate as a driver of evolutionary change. Curr. Biol. 19 (14), R575-R583.

Esquerré, D., Brennan, I.G., Catullo, R.A., Torres-Pérez, F., Keogh, J.S., 2019. How mountains shape biodiversity: the role of the Andes in biogeography, diversification, and reproductive biology in South America's most species-rich lizard radiation (Squamata: Liolaemidae). Evolution 73 (2), 214-230.

Etienne, R.S., Haegeman, B., Stadler, T., Aze, T., Pearson, P.N., Purvis, A., Phillimore, A. B., 2012. Diversity-dependence brings molecular phylogenies closer to agreement with the fossil record. Proc. R. Soc. B Biol. Sci. 279 (1732), 1300-1309.

Ezard, T.H., Aze, T., Pearson, P.N., Purvis, A., 2011. Interplay between changing climate and species' ecology drives macroevolutionary dynamics. Science 332 (6027) 349-351.

Ezard, T.H., Quental, T.B., Benton, M.J., 2016. The Challenges to Inferring the Regulators of Biodiversity in Deep Time. The Royal Society.

Fan, J.-X., Shen, S.-Z., Erwin, D.H., Sadler, P.M., MacLeod, N., Cheng, Q.-M., Hou, X.-D., Yang, J., Wang, X.-D., Wang, Y., 2020. A high-resolution summary of Cambrian to Early Triassic marine invertebrate biodiversity. Science 367 (6475), 272-277.

Fauquette, S., Bernet, M., Suc, J.-P., Grosjean, A.-S., Guillot, S., Van Der Beek, P., Jourdan, S., Popescu, S.-M., Jiménez-Moreno, G., Bertini, A., 2015. Quantifying the Eocene to Pleistocene topographic evolution of the southwestern Alps, France and Italy. Earth Planet. Sci. Lett. 412, 220-234.

Favre, A., Päckert, M., Pauls, S.U., Jähnig, S.C., Uhl, D., Michalak, I., Muellner-Riehl, A. N., 2015. The role of the uplift of the Qinghai-Tibetan Plateau for the evolution of Tibetan biotas. Biol. Rev. 90 (1), 236-253.

Favre, A., Michalak, I., Chen, C.H., Wang, J.C., Pringle, J.S., Matuszak, S., Sun, H., Yuan, Y.M., Struwe, L., Muellner-Riehl, A.N., 2016. Out-of-Tibet: the spatio-temporal evolution of Gentiana (Gentianaceae). J. Biogeogr. 43 (10), 1967-1978.

Fiorella, R.P., Poulsen, C.J., Zolá, R.S.P., Jeffery, M.L., Ehlers, T.A., 2015. Modern and long-term evaporation of central Andes surface waters suggests paleo archives underestimate Neogene elevations. Earth Planet. Sci. Lett. 432, 59-72.

Fosdick, J.C., Romans, B.W., Fildani, A., Bernhardt, A., Calderón, M., Graham, S.A., 2011. Kinematic evolution of the Patagonian retroarc fold-and-thrust belt and Magallanes foreland basin, Chile and Argentina, 51 30' S. Bulletin 123 (9-10), $1679-1698$.

Fouquet, A., Blotto, B.L., Maronna, M.M., Verdade, V.K., Juncá, F.A., de Sá, R., Rodrigues, M.T., 2013. Unexpected phylogenetic positions of the genera Rupirana and Crossodactylodes reveal insights into the biogeography and reproductive evolution of leptodactylid frogs. Mol. Phylogenet. Evol. 67 (2), 445-457.

Fouquet, A., Santana Cassini, C., Fernando Baptista Haddad, C., Pech, N., Trefaut Rodrigues, M., 2014. Species delimitation, patterns of diversification and historical 
biogeography of the $\mathrm{N}$ eotropical frog genus Adenomera (Anura, Leptodactylidae). J. Biogeogr. 41 (5), 855-870.

García-Rodríguez, A., Martínez, P.A., Oliveira, B.F., Velasco, J.A., Pyron, R.A., Costa, G. C., 2021. Amphibian speciation rates support a general role of mountains as biodiversity pumps. American Naturalist, 198(3) (September 2021).

Garzione, C.N., Hoke, G.D., Libarkin, J.C., Withers, S., MacFadden, B., Eiler, J., Ghosh, P., Mulch, A., 2008. Rise of the Andes. Science 320 (5881), 1304-1307.

Garzione, C.N., Auerbach, D.J., Smith, J.J.-S., Rosario, J.J., Passey, B.H., Jordan, T.E., Eiler, J.M., 2014. Clumped isotope evidence for diachronous surface cooling of the Altiplano and pulsed surface uplift of the Central Andes. Earth Planet. Sci. Lett. 393, $173-181$.

Gentry, A.H., 1982. Neotropical floristic diversity: phytogeographical connections between Central and South America, Pleistocene climatic fluctuations, or an accident of the Andean orogeny? Ann. Mo. Bot. Gard. 69 (3), 557-593.

Giambiagi, L., Mescua, J., Bechis, F., Hoke, G., Suriano, J., Spagnotto, S., Moreiras, S.M., Lossada, A., Mazzitelli, M., Dapoza, R.T., 2016. Cenozoic orogenic evolution of the southern central Andes (32-36 S). In: Growth of the Southern Andes. Springer, pp. 63-98.

Goldberg, E.E., Lancaster, L.T., Ree, R.H., 2011. Phylogenetic inference of reciprocal effects between geographic range evolution and diversification. Syst. Biol. 60 (4), $451-465$.

Gómez, E., Jordan, T.E., Allmendinger, R.W., Cardozo, N., 2005a. Development of the Colombian foreland-basin system as a consequence of diachronous exhumation of the northern Andes. Geol. Soc. Am. Bull. 117 (9-10), 1272-1292.

Gómez, E., Jordan, T.E., Allmendinger, R.W., Hegarty, K., Kelley, S., 2005b. Syntectonic Cenozoic sedimentation in the northern middle Magdalena Valley Basin of Colombia and implications for exhumation of the Northern Andes. Geol. Soc. Am. Bull. 117 (5-6), 547-569.

Gregory-Wodzicki, K.M., 2000. Uplift history of the Central and Northern Andes: a review. GSA Bull. 112 (7), 1091-1105.

Gregory-Wodzicki, K.M., McIntosh, W., Velasquez, K., 1998. Climatic and tectonic implications of the late Miocene Jakokkota flora, Bolivian Altiplano. J. S. Am. Earth Sci. 11 (6), 533-560.

Hagen, O., Flück, B., Fopp, F., Cabral, J.S., Hartig, F., Pontarp, M., Rangel, T.F., Pellissier, L., 2021. gen3sis: a general engine for eco-evolutionary simulations of the processes that shape Earth's biodiversity. PLoS Biol. 19 (7), e3001340.

Hannisdal, B., Peters, S.E., 2011. Phanerozoic Earth system evolution and marine biodiversity. Science 334 (6059), 1121-1124.

Hansen, J., Sato, M., Russell, G., Kharecha, P., 2013. Climate sensitivity, sea level and atmospheric carbon dioxide. Philos. Trans. R. Soc. A Math. Phys. Eng. Sci. 371 (2001), 20120294.

Hazzi, N.A., Moreno, J.S., Ortiz-Movliav, C., Palacio, R.D., 2018. Biogeographic regions and events of isolation and diversification of the endemic biota of the tropical Andes. Proc. Natl. Acad. Sci. 115 (31), 7985-7990.

Hembry, D.H., Weber, M.G., 2020. Ecological interactions and macroevolution: a new field with old roots. Annu. Rev. Ecol. Evol. Syst. 51.

Hernández, R., Jordan, T., Farjat, A.D., Echavarría, L., Idleman, B., Reynolds, J., 2005. Age, distribution, tectonics, and eustatic controls of the Paranense and Caribbean marine transgressions in southern Bolivia and Argentina. J. S. Am. Earth Sci. 19 (4), 495-512.

Höhna, S., Stadler, T., Ronquist, F., Britton, T., 2011. Inferring speciation and extinction rates under different sampling schemes. Mol. Biol. Evol. 28 (9), 2577-2589.

Hoke, G.D., Giambiagi, L.B., Garzione, C.N., Mahoney, J.B., Strecker, M.R., 2014. Neogene paleoelevation of intermontane basins in a narrow, compressional mountain range, southern Central Andes of Argentina. Earth Planet. Sci. Lett. 406, $153-164$.

Hoorn, C., Wesselingh, F., 2011. Amazonia: Landscape and Species Evolution: A Look into The Past. John Wiley \& Sons.

Hoorn, C., Wesselingh, F., Ter Steege, H., Bermudez, M., Mora, A., Sevink, J., Sanmartín, I., Sanchez-Meseguer, A., Anderson, C., Figueiredo, J., 2010. Amazonia through time: Andean uplift, climate change, landscape evolution, and biodiversity. Science 330 (6006), 927-931.

Hoorn, C., Mosbrugger, V., Mulch, A., Antonelli, A., 2013. Biodiversity from mountain building. Nat. Geosci. 6, 154. Correspondence. https://doi.org/10.1038/ngeo1742.

Hoorn, C., Perrigo, A., Antonelli, A., 2018. Mountains, Climate and Biodiversity. John Wiley \& Sons.

Horton, B.K., 2018. Sedimentary record of Andean mountain building. Earth Sci. Rev. 178, 279-309.

Hughes, C.E., Atchison, G.W., 2015. The ubiquity of alpine plant radiations: from the Andes to the Hengduan Mountains. New Phytol. 207 (2), 275-282.

Hughes, C., Eastwood, R., 2006. Island radiation on a continental scale: exceptional rates of plant diversification after uplift of the Andes. Proc. Natl. Acad. Sci. 103 (27), 10334-10339.

Hutter, C.R., Lambert, S.M., Wiens, J.J., 2017. Rapid diversification and time explain amphibian richness at different scales in the Tropical Andes, Earth's most biodiverse hotspot. Am. Nat. 190 (6), 828-843.

Jabbour, F., Renner, S.S., 2012. A phylogeny of Delphinieae (Ranunculaceae) shows that Aconitum is nested within Delphinium and that Late Miocene transitions to long life cycles in the Himalayas and Southwest China coincide with bursts in diversification. Mol. Phylogenet. Evol. 62 (3), 928-942.

Jaramillo, C., Rueda, M.J., Mora, G., 2006. Cenozoic plant diversity in the Neotropics. Science 311 (5769), 1893-1896.

Josse, C., Cuesta, F., Navarro, G., Barrena, V., Becerra, M.T., Cabrera, E., ChacónMoreno, E., Ferreira, W., Peralvo, M., Saito, J., 2011. Physical geography and ecosystems in the tropical Andes. In: Herzog, S.K., Martínez, R., Tiessen, P.M. Jørgensen Y.H., (comps.) (Eds.), Climate Change and Biodiversity in the Tropical
Andes. São José dos Campos y París. Instituto Interamericano para la Investigación del Cambio Global y Comité Científico sobre Problemas del Medio Ambiente.

Kar, N., Garzione, C.N., Jaramillo, C., Shanahan, T., Carlotto, V., Pullen, A., Moreno, F., Anderson, V., Moreno, E., Eiler, J., 2016. Rapid regional surface uplift of the northern Altiplano plateau revealed by multiproxy paleoclimate reconstruction. Earth Planet. Sci. Lett. 447, 33-47.

Kohn, M., Spear, F., Harrison, T., Dalziel, I., 1995. 40Ar/39Ar geochronology and P-T-t paths from the Cordillera Darwin metamorphic complex, Tierra del Fuego, Chile. J. Metamorph. Geol. 13 (2), 251-270.

Körner, C., Jetz, W., Paulsen, J., Payne, D., Rudmann-Maurer, K., Spehn, E.M., 2017. A global inventory of mountains for bio-geographical applications. Alp. Bot. 127 (1), $1-15$.

Lagomarsino, L.P., Condamine, F.L., Antonelli, A., Mulch, A., Davis, C.C., 2016. The abiotic and biotic drivers of rapid diversification in A ndean bellflowers (Campanulaceae). New Phytol. 210 (4), 1430-1442.

Lehtonen, S., Silvestro, D., Karger, D.N., Scotese, C., Tuomisto, H., Kessler, M., Peña, C., Wahlberg, N., Antonelli, A., 2017. Environmentally driven extinction and opportunistic origination explain fern diversification patterns. Sci. Rep. 7 (1), 1-12.

Leier, A., McQuarrie, N., Garzione, C., Eiler, J., 2013. Stable isotope evidence for multiple pulses of rapid surface uplift in the Central Andes, Bolivia. Earth Planet. Sci. Lett. 371, 49-58.

Lenevue, J., Chichvarkhin, A., Wahlberg, N., 2009. Varying rates of diversification in the genus Melitaea (Lepidoptera: Nymphalidae) during the past 20 million years. Biol. J. Linn. Soc. 97 (2), 346-361. https://doi.org/10.1111/j.1095-8312.2009.01208.x.

Linder, H.P., 2008. Plant species radiations: where, when, why? Philos. Trans. Royal Soc. B: Biol. Sci. 363 (1506), 3097-3105.

Liow, L.H., Reitan, T., Harnik, P.G., 2015. Ecological interactions on macroevolutionary time scales: clams and brachiopods are more than ships that pass in the night. Ecol. Lett. 18 (10), 1030-1039.

Liu, X., Xu, Q., Ding, L., 2016. Differential surface uplift: Cenozoic paleoelevation history of the Tibetan Plateau. Sci. China Earth Sci. 59 (11), 2105-2120.

Luebert, F., Weigend, M., 2014. Phylogenetic insights into Andean plant diversification. Front. Ecol, Evol. 2, 27.

Maddison, W.P., Midford, P.E., Otto, S.P., 2007. Estimating a binary character's effect on speciation and extinction. Syst. Biol. 56 (5), 701-710.

Madrinán, S., Cortés, A.J., Richardson, J.E., 2013. Páramo is the world's fastest evolving and coolest biodiversity hotspot. Front. Genet. 4, 192.

Mao, K., Hao, G., Liu, J., Adams, R.P., Milne, R.I., 2010. Diversification and biogeography of Juniperus (Cupressaceae): variable diversification rates and multiple intercontinental dispersals. New Phytol. 188 (1), 254-272.

Marx, F.G., Uhen, M.D., 2010. Climate, critters, and cetaceans: Cenozoic drivers of the evolution of modern whales. Science 327 (5968), 993-996.

Mathiasen, P., Premoli, A.C., 2010. Out in the cold: genetic variation of Nothofagus pumilio (Nothofagaceae) provides evidence for latitudinally distinct evolutionary histories in austral South America. Mol. Ecol. 19 (2), 371-385.

Mayhew, P.J., Bell, M.A., Benton, T.G., McGowan, A.J., 2012. Biodiversity tracks temperature over time. Proc. Natl. Acad. Sci. 109 (38), 15141-15145.

Mittermeier, R., Gil, P., Hoffmann, M., Pilgrim, J., 2004. Hotspots: earth's biologically richest and most threatened terrestrial ecoregions. Conserv. Int 400.

Molnar, P., England, P., Martinod, J., 1993. Mantle dynamics, uplift of the Tibetan Plateau, and the Indian monsoon. Rev. Geophys. 31 (4), 357-396.

Montes, C., Cardona, A., Jaramillo, C., Pardo, A., Silva, J., Valencia, V., Ayala, C., PérezAngel, L., Rodriguez-Parra, L., Ramirez, V., 2015. Middle Miocene closure of the Central American seaway. Science 348 (6231), 226-229.

Montes, C., Rodriguez-Corcho, A.F., Bayona, G., Hoyos, N., Zapata, S., Cardona, A., 2019. Continental margin response to multiple arc-continent collisions: the northern Andes-Caribbean margin. Earth Sci. Rev. 198, 102903.

Morlon, H., 2014. Phylogenetic approaches for studying diversification. Ecol. Lett. 17 (4), 508-525.

Morlon, H., Parsons, T.L., Plotkin, J.B., 2011. Reconciling molecular phylogenies with the fossil record. Proc. Natl. Acad. Sci. 108 (39), 16327-16332.

Morlon, H., Lewitus, E., Condamine, F.L., Manceau, M., Clavel, J., Drury, J., 2016. RPANDA: an R package for macroevolutionary analyses on phylogenetic trees. Methods Ecol. Evol. 7 (5), 589-597.

Muellner-Riehl, A.N., Schnitzler, J., Kissling, W.D., Mosbrugger, V., Rijsdijk, K.F., Seijmonsbergen, A.C., Versteegh, H., Favre, A., 2019. Origins of global mountain plant biodiversity: testing the 'mountain-geobiodiversity hypothesis'. J. Biogeogr. 46, 2826-2838.

Muñoz-Ortiz, A., Velásquez-Álvarez, Á.A., Guarnizo, C.E., Crawford, A.J., 2015. Of peaks and valleys: testing the roles of orogeny and habitat heterogeneity in driving allopatry in mid-elevation frogs (Aromobatidae: Rheobates) of the northern Andes. J. Biogeogr. 42 (1), 193-205.

Mutke, J., Jacobs, R., Meyers, K., Henning, T., Weigend, M., 2014. Diversity patterns of selected Andean plant groups correspond to topography and habitat dynamics, not orogeny. Front. Genet. 5, 351.

Myers, N., Mittermeier, R.A., Mittermeier, C.G., Da Fonseca, G.A., Kent, J., 2000 Biodiversity hotspots for conservation priorities. Nature 403 (6772), 853-858.

Nakajima, T., Danhara, T., Iwano, H., Chinzei, K., 2006. Uplift of the Ou Backbone Range in Northeast Japan at around $10 \mathrm{Ma}$ and its implication for the tectonic evolution of the eastern margin of Asia. Palaeogeogr. Palaeoclimatol. Palaeoecol. 241 (1), 28-48.

Nee, S., 2006. Birth-death models in macroevolution. Annu. Rev. Ecol. Evol. Syst. 37, $1-17$.

Nee, S., Holmes, E.C., May, R.M., Harvey, P.H., 1994. Extinction rates can be estimated from molecular phylogenies. Philos. Trans. R. Soc. Lond. B Biol. Sci. 344 (1307), $77-82$. 
Nevado, B., Contreras-Ortiz, N., Hughes, C., Filatov, D.A., 2018. Pleistocene glacial cycles drive isolation, gene flow and speciation in the high-elevation Andes. New Phytol. 219 (2), 779-793.

O’Dea, A., Lessios, H.A., Coates, A.G., Eytan, R.I., Restrepo-Moreno, S.A., Cione, A.L., Collins, L.S., De Queiroz, A., Farris, D.W., Norris, R.D., 2016. Formation of the Isthmus of Panama. Sci. Adv. 2 (8), e1600883.

Pannetier, T., Martinez, C., Bunnefeld, L., Etienne, R.S., 2021. Branching patterns in phylogenies cannot distinguish diversity-dependent diversification from timedependent diversification. Evolution 75 (1), 25-38.

Pérez-Escobar, O.A., Gottschling, M., Chomicki, G., Condamine, F.L., Klitgård, B.B., Pansarin, E., Gerlach, G., 2017a. Andean mountain building did not preclude dispersal of lowland epiphytic orchids in the Neotropics. Sci. Rep. 7 (1), 1-10.

Pérez-Escobar, O.A., Chomicki, G., Condamine, F.L., Karremans, A.P., Bogarín, D. Matzke, N.J., Silvestro, D., Antonelli, A., 2017b. Recent origin and rapid speciation of Neotropical orchids in the world's richest plant biodiversity hotspot. New Phytol. 215 (2), 891-905.

Pigot, A.L., Phillimore, A.B., Owens, I.P., Orme, C.D.L., 2010. The shape and temporal dynamics of phylogenetic trees arising from geographic speciation. Syst. Biol. 59 (6), 660-673.

Pigot, A.L., Sheard, C., Miller, E.T., Bregman, T.P., Freeman, B.G., Roll, U., Seddon, N., Trisos, C.H., Weeks, B.C., Tobias, J.A., 2020. Macroevolutionary convergence connects morphological form to ecological function in birds. Nat. Ecol. Evol. 4 (2), 230-239.

Quade, J., Dettinger, M., Carrapa, B., DeCelles, P., Murray, K., Huntington, K., Cartwright, A., Canavan, R., Gehrels, G., Clementz, M., 2015. The growth of the central Andes, 22 S-26 S. Geol. Soc. Am. Mem. 212, 277-308.

Quental, T.B., Marshall, C.R., 2010. Diversity dynamics: molecular phylogenies need the fossil record. Trends Ecol. Evol. 25 (8), 434-441.

Quintero, I., Jetz, W., 2018. Global elevational diversity and diversification of birds. Nature 555 (7695), 246-250.

Quintero, I., Keil, P., Jetz, W., Crawford, F.W., 2015. Historical biogeography using species geographical ranges. Syst. Biol. 64 (6), 1059-1073.

Rabosky, D.L., Lovette, I.J., 2008. Explosive evolutionary radiations: decreasing speciation or increasing extinction through time? Evolution 62 (8), 1866-1875.

Rahbek, C., Borregaard, M.K., Antonelli, A., Colwell, R.K., Holt, B.G., Nogues-Bravo, D. Rasmussen, C.M., Richardson, K., Rosing, M.T., Whittaker, R.J., 2019a. Building mountain biodiversity: geological and evolutionary processes. Science 365 (6458), 1114-1119.

Rahbek, C., Borregaard, M.K., Colwell, R.K., Dalsgaard, B., Holt, B.G., MoruetaHolme, N., Nogues-Bravo, D., Whittaker, R.J., Fjeldså, J., 2019b. Humboldt's enigma: what causes global patterns of mountain biodiversity? Science 365 (6458), 1108-1113.

Rangel, T.F., Edwards, N.R., Holden, P.B., Diniz-Filho, J.A.F., Gosling, W.D., Coelho, M T.P., Cassemiro, F.A., Rahbek, C., Colwell, R.K., 2018. Modeling the ecology and evolution of biodiversity: biogeographical cradles, museums, and graves. Science 361 (6399), eaar5452.

Ree, R.H., Smith, S.A., 2008. Maximum likelihood inference of geographic range evolution by dispersal, local extinction, and cladogenesis. Syst. Biol. 57 (1), 4-14.

Réjaud, A., Rodrigues, M.T., Crawford, A.J., Castroviejo-Fisher, S., Jaramillo, A.F., Chaparro, J.C., Glaw, F., Gagliardi-Urrutia, G., Moravec, J., De la Riva, I.J., 2020. Historical biogeography identifies a possible role of Miocene wetlands in the diversification of the Amazonian rocket frogs (Aromobatidae: Allobates) J. Biogeogr. 47 (11), 2472-2482.

Renner, S.S., 2016. Available data point to a 4-km-high Tibetan Plateau by $40 \mathrm{Ma}$, but 100 molecular-clock papers have linked supposed recent uplift to young node ages. J. Biogeogr. 43 (8), 1479-1487.

Ricklefs, R.E., 2007. Estimating diversification rates from phylogenetic information. Trends Ecol. Evol. 22 (11), 601-610.

Rohrmann, A., Sachse, D., Mulch, A., Pingel, H., Tofelde, S., Alonso, R.N., Strecker, M.R. 2016. Miocene orographic uplift forces rapid hydrological change in the southern central Andes. Sci. Rep. 6, 35678. https://doi.org/10.1038/srep35678.

Rowley, D.B., Garzione, C.N., 2007. Stable isotope-based paleoaltimetry. Annu. Rev. Earth Planet. Sci. 35, 463-508.

Santos, J.C., Coloma, L.A., Summers, K., Caldwell, J.P., Ree, R., Cannatella, D.C., 2009. Amazonian amphibian diversity is primarily derived from late Miocene Andean lineages. PLoS Biol. 7 (3), e1000056.

Santos, M.T.T., de Magalhães, R.F., Lyra, M.L., Santos, F.R., Zaher, H., Giasson, L.O., Garcia, P.C., Carnaval, A.C., Haddad, C.F., 2020. Multilocus phylogeny of Paratelmatobiinae (Anura: Leptodactylidae) reveals strong spatial structure and previously unknown diversity in the Atlantic Forest hotspot. Mol. Phylogenet. Evol. 106819.

Sarmiento-Rojas, L.F., 2019. Cretaceous stratigraphy and paleo-facies maps of northwestern South America. In: Geology and Tectonics of Northwestern South America. Springer, pp. 673-747.
Saylor, J.E., Horton, B.K., 2014. Nonuniform surface uplift of the Andean plateau revealed by deuterium isotopes in Miocene volcanic glass from southern Peru. Earth Planet. Sci. Lett. 387, 120-131.

Scheuber, E., Mertmann, D., Ege, H., Silva-González, P., Heubeck, C., Reutter, K.-J., Jacobshagen, V., 2006. Exhumation and basin development related to formation of the central Andean plateau, 21 S. In: The Andes. Springer, pp. 285-301.

Schwery, O., Onstein, R.E., Bouchenak-Khelladi, Y., Xing, Y., Carter, R.J., Linder, H.P., 2015. As old as the mountains: the radiations of the Ericaceae. New Phytol. 207 (2), 355-367.

Sepulchre, P., Sloan, L.C., Fluteau, F., 2010. Modelling the response of Amazonian climate to the uplift of the Andean mountain range. Amazonia. In: Landscape and Species Evolution: A Look into the Past, pp. 211-222.

Silvestro, D., Salamin, N., Schnitzler, J., 2014. PyRate: a new program to estimate speciation and extinction rates from incomplete fossil data. Methods Ecol. Evol. 5 (10), 1126-1131.

Silvestro, D., Antonelli, A., Salamin, N., Quental, T.B., 2015. The role of clade competition in the diversification of North American canids. Proc. Natl. Acad. Sci. 112 (28), 8684-8689.

Silvestro, D., Salamin, N., Antonelli, A., Meyer, X., 2019. Improved estimation of macroevolutionary rates from fossil data using a Bayesian framework. Paleobiology 45 (4), 546-570.

Simpson, G.G., 1980. Splendid Isolation: The Curious History of South American Mammals.

Spicer, R.A., Su, T., Valdes, P.J., Farnsworth, A., Wu, F.-X., Shi, G., Spicer, T.E., Zhou, Z., 2020. Why the 'Uplift of the Tibetan Plateau' is a myth. Natl. Sci. Rev. 8 (1) https:// doi.org/10.1093/nsr/nwaa091.

Squeo, F.A., Veit, H., Arancio, G., Gutierrez, J.R., Arroyo, M.T., Olivares, N., 1993. Spatial heterogeneity of high mountain vegetation in the Andean desert zone of Chile. Mt. Res. Dev. 203-209.

Stadler, T., 2013. Recovering speciation and extinction dynamics based on phylogenies. J. Evol. Biol. 26 (6), 1203-1219.

Testo, W.L., Sessa, E., Barrington, D.S., 2019. The rise of the Andes promoted rapid diversification in Neotropical Phlegmariurus (Lycopodiaceae). New Phytol. 222 (1), 604-613.

Toussaint, E.F., Dias, F.M., Mielke, O.H., Casagrande, M.M., Sañudo-Restrepo, C.P., Lam, A., Morinière, J., Balke, M., Vila, R., 2019. Flight over the Proto-Caribbean seaway: phylogeny and macroevolution of Neotropical Anaeini leafwing butterflies. Mol. Phylogenet. Evol. 137, 86-103.

Uba, C.E., Heubeck, C., Hulka, C., 2006. Evolution of the late Cenozoic Chaco foreland basin, southern Bolivia. Basin Res. 18 (2), 145-170.

Vacher, J.-P., Kok, P.J., Rodrigues, M.T., Lima, J.D., Lorenzini, A., Martinez, Q., Fallet, M., Courtois, E.A., Blanc, M., Gaucher, P., 2017. Cryptic diversity in Amazonian frogs: Integrative taxonomy of the genus Anomaloglossus (Amphibia: Anura: Aromobatidae) reveals a unique case of diversification within the Guiana Shield. Mol. Phylogenet. Evol. 112, 158-173.

Valente, L.M., Phillimore, A.B., Etienne, R.S., 2015. Equilibrium and non-equilibrium dynamics simultaneously operate in the Galápagos islands. Ecol. Lett. 18 (8), $844-852$.

Veizer, J., Prokoph, A., 2015. Temperatures and oxygen isotopic composition of Phanerozoic oceans. Earth Sci. Rev. 146, 92-104.

Vergara, M., Levi, B., Nyström, J.O., Cancino, A., 1995. Jurassic and Early Cretaceous island arc volcanism, extension, and subsidence in the Coast Range of central Chile. Geol. Soc. Am. Bull. 107 (12), 1427-1440.

Villagómez, D., Spikings, R., Mora, A., Guzmán, G., Ojeda, G., Cortés, E., Van Der Lelij, R., 2011. Vertical tectonics at a continental crust-oceanic plateau plate boundary zone: Fission track thermochronology of the Sierra Nevada de Santa Marta, Colombia. Tectonics 30 (4).

Wang, L., Schneider, H., Zhang, X.-C., Xiang, Q.-P., 2012. The rise of the Himalaya enforced the diversification of SE Asian ferns by altering the monsoon regimes. BMC Plant Biol. 12 (1), 210. https://doi.org/10.1186/1471-2229-12-210.

Westerhold, T., Marwan, N., Drury, A.J., Liebrand, D., Agnini, C., Anagnostou, E. Barnet, J.S., Bohaty, S.M., De Vleeschouwer, D., Florindo, F., 2020. An astronomically dated record of Earth's climate and its predictability over the last 66 million years. Science 369 (6509), 1383-1387.

Wilf, P., Cúneo, N.R., Johnson, K.R., Hicks, J.F., Wing, S.L., Obradovich, J.D., 2003. High plant diversity in Eocene South America: evidence from Patagonia. Science 300 (5616), 122-125.

Xing, Y., Ree, R.H., 2017. Uplift-driven diversification in the Hengduan Mountains, a temperate biodiversity hotspot. Proc. Natl. Acad. Sci. 114 (17), E3444-E3451.

Ye, X.Y., Ma, P.F., Yang, G.Q., Guo, C., Zhang, Y.X., Chen, Y.M., Guo, Z.H., Li, D.Z., 2019. Rapid diversification of alpine bamboos associated with the uplift of the Hengduan Mountains. J. Biogeogr. 46 (12), 2678-2689.

Zaffos, A., Finnegan, S., Peters, S.E., 2017. Plate tectonic regulation of global marine animal diversity. Proc. Natl. Acad. Sci. 114 (22), 5653-5658. 